\title{
Dinamização Econômica e Agricultura Familiar: limites e desafios do apoio a Projetos de Infraestrutura (Proinf) em territórios rurais do Nordeste ${ }^{12}$
}

\author{
Emanoel Márcio Nunes ${ }^{3}$, Fátima de Lima Tôrres ${ }^{4}$, \\ Márcia Regina Farias da Silva ${ }^{5}$, Vinícius Claudino de Sá6 e \\ Kalianne Freire Godeiro-Nunes ${ }^{7}$
}

Resumo: O objetivo do presente artigo é analisar a importância do Apoio a Projetos de Infraestrutura e Serviços em Territórios (Proinf) no financiamento recente da estrutura de produção econômica da agricultura familiar de territórios rurais do Nordeste. A proposta é avaliar projetos que atuam através de ações de inclusão produtiva e de gestão social, a fim de garantir a dinamização econômica dos territórios. A metodologia foi definida pela Secretaria de Desenvolvimento Territorial (SDT), e a pesquisa de campo realizada utilizando o questionário de Avaliação de Projetos de Investimento (Q5). Assim sendo, cada projeto foi visitado e 18 questionários foram aplicados junto aos membros dos colegiados territoriais de seis projetos avaliados e monitorados. Como resultado, percebeu-se que poucos projetos foram implantados, especialmente de agroindústrias familiares. Contatou-se também que nenhum destes funciona. Esse resultado alerta para a urgência do ajuste do arranjo institucional nos territórios e da busca pela

1. Este trabalho é resultado de pesquisas desenvolvidas no âmbito da agricultura familiar e contou com auxílio financeiro do MDA/SDT/CNPq através do Edital 005/2009 - Gestão de Territórios Rurais.

2. Data de submissão: 28 de novembro de 2014. Data de aceite: 2 de setembro de 2015.

3. Universidade do Estado do Rio Grande do Norte (UERN), Mossoró-RN, Brasil. E-mail: emanoelnunes@uern.br

4. Universidade do Estado do Rio Grande do Norte (UERN), Mossoró-RN, Brasil. E-mail: fatmalima@hotmail.com

5. Universidade do Estado do Rio Grande do Norte (UERN), Mossoró-RN, Brasil. E-mail: mreginafarias@hotmail.com

6. Universidade do Estado do Rio Grande do Norte (UERN), Mossoró-RN, Brasil. E-mail: viniciusclaudino@gmail.com

7. Universidade do Estado do Rio Grande do Norte (UERN), Mossoró-RN, Brasil. E-mail: kaliannefgnunes@yahoo.com.br 
superação das fragilidades nas estruturas de gestão e de produção econômica da agricultura familiar, principalmente nos territórios Açu-Mossoró e Sertão do Apodi (RN).

Palavras-chaves: Agricultura familiar, política pública, território.

Abstract: The goal of this study is to analyze the importance of Support for Infrastructure Projects and Services in Territories (Proinf) in the recent financing of economic production structure of family farming rural areas of the Northeast Brazil. The idea is to assess projects as actions of productive inclusion and social management, to the economic dynamism of territories. The methodology has already been defined by the Territorial Development Secretariat (SDT), and field research make using the questionnaire Investment Project Evaluation (Q5). Visits were performed on each project and 18 questionnaires were sent to members of the territorial boards of six evaluated and monitored projects. As a result, it was noted that few projects were implemented, especially family farms, and that any of these works. This result points to the urgency in the institutional arrangement of the adjustment in the territories and to seek ways to overcome weaknesses in the management structures and economic production of family farming, especially in the Açu-Mossoró and Sertão do Apodi (RN) territories.

Key-words: Family farming, public policy, territory.

DOI - http://dx.doi.org/10.1590/1234-56781806-9479005303009

Classificação JEL: Q13, Q18, R11.

\section{Introdução}

O Brasil tem como características marcantes a diversidade e a heterogeneidade entre suas regiões, principalmente no tocante à infraestrutura de produção no seu meio rural, onde cada região apresenta especificidades que produzem e reproduzem disparidades, sejam econômicas ou sociais, revelando, assim, desigualdades regionais. Nas últimas décadas, visando reduzir as desigualdades e incorporar incentivos para proporcionar o desenvolvimento regional, o debate e a ação pública do Estado têm aflorado na formulação e implantação de políticas territoriais voltadas para o financiamento da estrutura de produção da agricultura familiar.

Nesta perspectiva, em 2003, a Secretaria de Desenvolvimento Territorial do Ministério do Desenvolvimento Agrário (SDT/MDA) adotou a estratégia da territorialização do desenvolvimento rural, por meio do Programa Desenvolvimento Sustentável de Territórios Rurais (Pronat), que teve início em 2004, em 65 territórios. Em 2006, essa política abrangia 118 territórios rurais, contando, em 2012, com 164 territórios rurais compostos por 2,5 mil municípios. Em 2008, foi criado o Programa Territórios da Cidadania (PTC), abrangendo 120 territórios em todo o País e com o objetivo de dinamizar a economia das regióes com altos índices de pobreza, economia agrícola de base familiar precária e menor acesso às políticas públicas.

Das regiões brasileiras, a Nordeste é a que ainda apresenta um meio rural de economia agrícola de base familiar mais precária, sendo esta, ao mesmo tempo, causa e efeito da ausência, fragilidade e aguda deficiência de estrutura de produção econômica. Essa realidade leva a uma discussão em torno dos fatores que determinam o surgimento da inovação e do desenvolvimento ao longo dos anos; problema que preocupa tanto lideranças políticas como pesquisadores. Esta questão se coloca quando a finalidade é reduzir desigualdades regionais, considerando que os baixos indicadores de desenvolvimento encontrados no País, especialmente em regiões como a Nordeste, tendem a revelar a deficiência e a inoperância na aplicação de políticas e uma marcante concentração geográfica. Dessa forma, ao longo das décadas, as políticas do Estado que visam reduzir as desigualdades regionais com a obtenção de melhores indicadores assumiram um caráter estratégico de políticas regionais.

As políticas regionais do Estado, desde os anos 1950 até meados dos anos 1980, possuíam um caráter centralizador e modernizador, e 
não respeitavam a cultura e a capacidade coletiva dos atores locais para colocar em prática as ações de desenvolvimento econômico. A instabilidade dos anos 1980 continuam na década de 1990, e é nesse período que o Estado redefine o seu papel e sinaliza para a ampliação da reforma agrária, criando o Programa Nacional de Fortalecimento da Agricultura Familiar (Pronaf), sendo este amplamente explorado pela literatura desde então. Mais recentemente, a partir dos anos 2000, um dos temas ainda pouco explorados sobre estudos rurais no Brasil é o financiamento da política de desenvolvimento territorial. Além disso, o tratamento das condições é relativamente escasso, sejam elas financeiras ou orçamentárias, para financiar mecanismos de política agrícola (com exceção do crédito rural) e/ou de desenvolvimento rural. Na esfera territorial isso é ainda menos evidente, ou seja, apesar do foco no desempenho das políticas, pouco se diz das condições de financiamento da política de desenvolvimento territorial.

Na verdade, o foco está nos projetos de custeio e investimentos geridos e financiados pela SDT, denominados Apoio aos Projetos de Infraestrutura e Serviços nos Territórios Rurais (Proinf). O Proinf é uma ação orçamentária do Pronat, cuja finalidade é financiar projetos de desenvolvimento territorial definidos pelos Colegiados Territoriais ${ }^{8}$ em seus Planos Territoriais de Desenvolvimento Rural Sustentável (PTDRS). O Proinf possui

8. De acordo com o PTDRS (2010), estes são fóruns territoriais de participação e de concertação criados no âmbito do Pronat, de caráter paritário $(50 \%$ de membros da sociedade civil e $50 \%$ do poder público), com a finalidade de planejamento, gestão e controle social de políticas públicas, articulando e fomentando programas e projetos na perspectiva do desenvolvimento territorial. Quanto ao seu arranjo institucional, os Colegiados são constituídos por três instâncias: a) Plenária: soberana, de caráter deliberativo e consultivo, constituída enquanto espaço político, representativo e democrático, de tomada das decisões estratégicas do desenvolvimento; b) Núcleo Diretivo: de caráter diretivo e técnico, estrutura de coordenação do processo de desenvolvimento a ser implantado no Território, através da articulação de arranjos institucionais formados para permitir a execução do planejado e c) Núcleo Técnico: espaço de apoio técnico ao processo de planejamento, elaboração e gestão, principalmente na materialização das propostas contidas no PTDRS. grande importância, especialmente para a região Nordeste, pois tem como prioridade financiar a estrutura de produção da agricultura familiar, objetivando a dinamização econômica através da inclusão produtiva, as quais exigem a gestão social para integrar as políticas nos territórios.

Diante disso, o objetivo é mostrar o alcance das ações do Proinf no financiamento da estrutura de produção da agricultura familiar (considerando a inovação na implantação de agroindústrias familiares) e sua eficiência e limites nos Territórios da Cidadania Açu-Mossoró e o Sertão do Apodi. Como elementos de análise têm-se os resultados de pesquisa alcançados por meio da avaliação e do seu acompanhamento e monitoramento na fase de implantação. Assim, a questão que se impõe é: o financiamento da estrutura de produção da agricultura familiar, através do Proinf, e a dinamização dos territórios têm ocorrido de forma satisfatória? A hipótese é de que as dificuldades do Proinf ocorreram mais na sua implantação, reflexo da insuficiente gestão social e da frágil articulação institucional para pactuar acordos via Colegiado, assim como do cumprimento dos pactos para a inclusão produtiva por intermédio de projetos de infraestrutura.

\section{Dinamização econômica}

\subsection{Evolução das políticas públicas para a agricultura familiar no Brasil}

De acordo com Leite e Werz Jr. (2012), a partir de 2003, as políticas brasileiras para financiar as ações de desenvolvimento territorial, especialmente o Programa Desenvolvimento Sustentável de Territórios Rurais (Pronat), herdaram erros e acertos de outro programa, o Programa Nacional de Fortalecimento da Agricultura Familiar (Pronaf), na sua linha "Infraestrutura e Serviços". As ações do Pronaf "Infraestrutura e Serviços", vigentes de 1998 a 2002, se destacaram pelo financiamento da infraestrutura de produção da agricultura familiar, visando criar dinâmicas de desenvolvimento rural em municípios de 
economia agrícola precária, por meio de um repasse médio de $\mathrm{R} \$ 150$ mil anuais, durante quatro anos. Os repasses financeiros, segundo Leite e Werz Jr. (2012), eram definidos pelos Planos Municipais de Desenvolvimento Rural (PMDRs) e discutidos no âmbito dos Conselhos Municipais de Desenvolvimento Rural (CMDRs) ${ }^{9}$, cuja existência era obrigatória para receber estes repasses. Cabe lembrar que o arranjo institucional dos CMDRs tinha forte influência do poder público e contava com a participação de entidades representativas da sociedade civil.

Vale ressaltar que, nas regióes brasileiras, a agricultura familiar tem financiado e construído a sua estrutura de produção através de dinâmicas endógenas e específicas de desenvolvimento rural, engendradas pelos agricultores em uma relação entre tecnologia e mercados, em que a localidade e a diversificação são, ao mesmo tempo, ambiente e resultado do que Ploeg (1994) define como estilos de agricultura ${ }^{10}$. Ao contrário dos modelos de inovação exógena (innovation production) da modernização agrícola, as dinâmicas de desenvolvimento rural se apresentam adequadas para o surgimento do que Ploeg et al. (2004) definem como sendo novidades (novelty production $)^{11}$, sendo que se verifica essa possibili-

9. De acordo com Moura (2007), os Conselhos Municipais de Desenvolvimento Rural (CMDRs) são órgãos consultivos criados pelo Poder Legislativo Municipal, sendo um arranjo institucional relacionado a um processo geral de desenvolvimento rural vinculado ao Plano Diretor Municipal (PDM). Para Moura (2007), o papel do CMDR é o de gestor do Plano Municipal de Desenvolvimento Rural (PMDR), e o de coordenador da elaboração do plano, acompanhamento e avaliação das ações planejadas, com a participação dos agricultores e da sociedade.

10. Para este autor, o estilo de agricultura (styles of farming) é um complexo, ou seja, um conjunto integrado de noções, normas, conhecimentos, experiências etc., apreendido por um grupo de agricultores em uma região especifica, e que descreve o modo com que a práxis da agricultura é levada adiante. Estes resultam de uma tipologização das formas familiares de agricultura, operacionalizada com base em variáveis que expressam situações de maior ou menor diversificação; neste caso, de práticas agrícolas e de estratégias.

11. Para este autor, inovações (innovation) e novidades (novelty) possuem definições, trajetórias e histórias distintas, sendo as primeiras exógenas e definidas como padrão, externas e globais; as segundas seriam endógenas e se caracterizariam pela contextualização, pela internalização e pela territorialização. dade no trabalho e na diversificação das unidades familiares de produção. Assim, a partir dos anos 1990 torna-se cada vez mais incontestável o reconhecimento da agricultura familiar para a transformação das estruturas do meio rural. Para Conterato et al. (2011), as políticas passam a valorizar temas como desenvolvimento endógeno, diversificação e mercantilização $0^{12}$, antes desprezados e tratados pelos defensores da modernização como residuais ou sem importância analítica.

Para a região Nordeste, segundo Souza (1997), a partir de 1970 o Estado financiou iniciativas voltadas para a modernização da agricultura, esta integrada à indústria, saindo do nível regional dos planos diretores para o nível do Plano Nacional de Desenvolvimento, o PND e, conforme Nunes e Schneider (2013), surgia a necessidade da integração nacional, tendo sido elaborados Planos de Desenvolvimento do Nordeste (PDNs). A partir disso, segundo Nunes e Schneider (2013), a política agrícola foi direcionada para financiar a estruturação econômica de programas governamentais, como o Programa de Redistribuição de Terras e da Agroindústria do Nordeste (Proterra), de 1971, e o Programa de Desenvolvimento de Áreas Integradas do Nordeste (Polonordeste), de 1974. Estes programas privilegiaram um modelo exportador baseado em grandes empresas e visavam superar as deficiências da estrutura de produção da agricultura do Nordeste, que reproduzia baixos índices de produtividade e de produção, utilizando uma base técnica tradicional.

Para a agricultura familiar, as políticas públicas de estruturação econômica foram direcionadas para projetos de menor alcance, mas que introduziam uma lógica interessante de inovação endógena através da diversificação de sistemas produtivos em dinâmicas regionais de

12. Aqui, a mercantilização é analisada como o resultado da menor ou maior dependência do mercado, cuja escolha pelo consumo de mais ou menos elementos externos ou internos produz movimentos que os afastam ou os aproximam de certos mercados nocivos a eles, como monopólios, oligopólios etc. Entretanto, isso não significa que se deva desprezar estes mercados, mas que é preciso capacitação para se relacionar com eles. Para uma visão mais geral, ver Larson e Gillespie Jr. (1991), Schneider (1997) e Buttel (2001). 
desenvolvimento rural. Conforme Sabourin (2010), depois da experiência do Programa Nordeste, de 1985 a 1988, a Superintendência do Desenvolvimento do Nordeste (Sudene) implantou o Projeto de Apoio ao Pequeno Produtor Rural (PAPP), entre 1988 e 1992, com financiamento do Banco Mundial. Este programa buscou introduzir instituições importantes no ambiente da agricultura familiar, a exemplo do cooperativismo e do associativismo, com vistas à implantação de agroindústrias familiares. Para Sabourin (2010), o último período do PAPP, de 1993 a 1997, o qual passou a ser chamado de Programa de Combate à Pobreza Rural (PCPR), foi marcado por uma nova direção da política pública, ou seja, para ações de combate à pobreza e para grupos sociais específicos, sempre por meio da participação coletiva. Esta ação, que sempre priorizou a estruturação econômica de agricultores familiares via agroindústrias de pequeno porte, foi difundida em países da África e da América Latina sob o nome de Community Driven Development ${ }^{13}$, que iniciou sua experiência no México e no Brasil no início dos anos 1980 (SABOURIN, 2010, p. 145).

Ainda na primeira metade dos anos 1980, conforme Nunes e Schneider (2013), os instrumentos de política agrícola fundamentados na revolução verde encontram dificuldades diante da instabilidade macroeconômica que assolava a economia brasileira, iniciando o declínio dos modelos exógenos e especializados de modernização agrícola. O desemprego, a degradação ambiental, a pobreza rural etc. fizeram com que o modelo exógeno fosse questionado, tornando o ambiente favorável para movimentos de reinvindicação, como as demandas por crédito, reforma agrária, pelas ações de combate à pobreza, entre outros, a exemplo das ações apoiadas pelo Banco

13. O Community Driven Development é uma abordagem coletiva dos programas do Banco Mundial que defende o controle sobre as decisões de planejamento e de recursos para projetos de desenvolvimento para os grupos comunitários. Este programa opera sob os princípios da governança local, da capacitação participativa e de mais autonomia administrativa. O Banco Mundial reconhece que esta abordagem sempre foi um importante elemento para a redução da pobreza e para o desenvolvimento rural sustentável.
Mundial, a ponto de forçar o Estado a redefinir suas políticas. Tal conjuntura tornou-se adequada para afirmar a agricultura familiar como importante segmento da economia e intensificar ações que alcançassem os agricultores familiares, já que, durante décadas, a maioria destes não foi contemplada pelas políticas.

Na região Nordeste, especialmente nos anos 1980, o apoio à organização e ao financiamento da estrutura de produção econômica da agricultura familiar permite constatar que programas governamentais, como o Proterra e o Polonordeste, assim como a abordagem Community Driven Development, não alcançaram os resultados esperados. Apesar de programas como estes terem buscado a introdução de agroindústrias de pequeno porte e, no caso deste último, as ações terem condicionado a liberação dos recursos financeiros apenas para organizações coletivas, estas ações não se traduziram em desenvolvimento. Sugere-se, portanto, que a causa maior do não desenvolvimento vem da própria abordagem coletiva ${ }^{14}$ dos programas, em que os problemas sempre residiram na natureza, na elaboração e nos conteúdos dos projetos ${ }^{15}$ de estruturação econômica (SABOURIN, 2010, p. 155).

14. Neste caso, a abordagem coletiva diz respeito às formas de aproximação dos programas de financiamento da estrutura econômica (Banco Mundial, Pronaf, Proinf etc.) com as comunidades em que são implantados os projetos produtivos. Historicamente, essa abordagem tem sido realizada com a exigência por parte dos programas da criação pelas comunidades dos dispositivos coletivos, estes últimos como condição para o recebimento dos recursos financeiros. Essa abordagem coletiva possibilitou, ao longo dos últimos 30 anos, a criação de organizações sem instituição (associações sem o associativismo, cooperativas sem o cooperativismo etc.), numa lógica de criação do "corpo sem a alma", de forma que a quase totalidade da estrutura de produção (casas de farinha, entrepostos de mel etc.) financiada e vinculada a estas organizações jamais funcionou.

15. Os programas possuíam a concepção de trabalhar a abordagem coletiva a partir da construção de agroindústrias familiares com padrão moderno e atualizado. No entanto, a estruturação econômica passou a ser realizada muitas vezes por meio de tecnologias já obsoletas, e da construção de instalações inadequadas, o que levou a travar o processo de implantação e sequer iniciar o funcionamento da quase totalidade das unidades de produção. Na verdade, essa distorção vem, inclusive, da deficiência do processo de elaboração dos projetos, refletido na pouca qualificação dos elaboradores que compromete profundamente a qualidade dos conteúdos desses projetos. 
Especialmente para os agricultores familiares do Nordeste, os investimentos mostraram-se bastante adaptados para implantar agroindústrias de pequeno porte e infraestruturas tradicionais, a exemplo de casas de farinha, pequenas barragens de terra e armazéns ou silos para guardar grãos e forragens. Estes projetos estimulavam o surgimento de associações e de cooperativas; dentre elas, uma parte se tornou inativa e o acesso ao crédito para a produção econômica foi apenas simbólico. Especialmente no Nordeste, a abordagem Community Driven Development permitiu testar dois tipos de instrumentos participativos no âmbito da linha de Apoio às Pequenas Comunidades Rurais (APCR), a saber: os Projetos de Crédito Comunitário (PCC), destinados aos equipamentos coletivos, e os Conselhos Municipais de Desenvolvimento Rural (CMDR) que, de acordo com Abramovay (2001), seriam retomados posteriormente no âmbito dos planos de desenvolvimento sustentável do Nordeste em 1994 (SABOURIN, 2010, p. 145-146).

Os programas governamentais dos anos 1980 representaram mais ações de governo do que políticas de Estado, que estavam sujeitas às descontinuidades quando da mudança dos governos ou de restrições por parte das organizações internacionais de financiamento. $\mathrm{Na}$ verdade, representaram tentativas, a maioria ilusórias, de intervenções públicas que não levaram a pouco ou nada. Neste contexto, conforme Nunes e Schneider (2013), no início dos anos 1990, as demandas dos movimentos de reinvindicação agiram no sentido de fazer com que as políticas públicas sinalizassem para processos de diferenciação dos mecanismos de políticas agrárias e agrícolas e de diversificação da agricultura familiar, devendo, portanto, serem dedicados ao desenvolvimento rural sustentável. Como um resultado das reivindicações, conforme Nunes e Schneider (2013), dentre as ações deste período podem ser destacadas a ampliação da reforma agrária e a criação do Programa Nacional de Fortalecimento da Agricultura Familiar (Pronaf), em 1996. As políticas públicas para a agricul- tura familiar dos anos 1990, caracterizadas como políticas de desenvolvimento, tiveram, a partir de então, um avanço importante do ponto de vista de sua concepção, assim como passaram a considerar as especificidades do público-alvo: os agricultores familiares (SABOURIN, 2010, p. 144).

Quanto ao Pronaf, segundo Leite e Werz Jr (2012), ao longo da implantação da sua linha "Infraestrutura e Serviços", que durou de 1998 a 2002, algumas dificuldades afloraram, questionando a pertinência e a viabilidade da unidade municipal enquanto lugar de planejamento e organização que visava a promoção do desenvolvimento rural. Além disso, em várias localidades brasileiras ficou evidente que o poder público municipal atuava sob uma lógica clientelista e altamente subordinada aos interesses das oligarquias locais, comprometendo a demanda dos projetos e a sua execução. Os repasses financeiros, consoante Leite e Werz Jr (2012), eram definidos pelos Planos Municipais de Desenvolvimento Rural (PMDRs) e discutidos no âmbito dos Conselhos Municipais de Desenvolvimento Rural (CMDRs), sendo estes uma exigência (ou abordagem coletiva) para receber os recursos.

Das políticas de desenvolvimento dos anos 1990, o Pronaf, muito além da sua linha "Infraestrutura e Serviços", se configura como um poderoso mecanismo de política, sendo estratégico para um desenvolvimento regional dinamizado pela agricultura familiar. Obviamente que, para isso, o referido programa deveria se converter em projeto prioritário, integrado a outras políticas agrárias de oferta, a exemplo da reforma agrária, assim como a políticas agrícolas territoriais de demanda dos anos 2000, como o Programa de Aquisição de Alimentos (PAA) e do Programa Nacional de Alimentação Escolar (PNAE). Além do Pronaf, do PAA e do PNAE, cabe destacar os esforços recentes no sentido de criar e ampliar a infraestrutura de produção econômica da agricultura familiar no âmbito da política territorial, a exemplo do Apoio aos Projetos de Infraestrutura e Serviços nos Territórios Rurais (Proinf). 


\subsection{Estruturação econômica, inclusão produtiva e gestão social nos territórios}

A afirmação da agricultura familiar passa pela sua estruturação, a qual deve ser construída com um distanciamento gradual ${ }^{16}$ de mercados monopolistas. Saccomandi (1998) afirma que, na perspectiva institucional, este afastamento é necessário para um funcionamento mais adequado da agricultura familiar, objetivando o alcance de mais autonomia e da sua dinamização em nível micro. Para Nunes et al. (2014), a dinamização enfatiza e exige a existência e/ou construção de uma estrutura de produção econômica que possibilite a agregação de valor, considerando a diversificação de produtos locais, além de estimular a organização coletiva e a inovação tecnológica e gerencial para alcançar eficiência e competitividade no âmbito territorial. Com base na realidade da região Sul do Brasil, Santos Junior e Waquil (2012) constatam que as agroindústrias têm sido vistas como uma importante estratégica para agricultores familiares, contribuindo para a dinamização econômica em nível micro, por meio da articulação dos atores em redes de cooperação e com a concepção de cadeias e de arranjos institucionais. Nesse sentido, segundo Santos Junior e Waquil (2012), iniciativas como as agroindústrias familiares tendem a possibilitar condições para que se desenvolvam tecnologias e sistemas de gestão que se adequem à utilização dos recursos locais (do território) e ao seu estágio de desenvolvimento.

Em sua obra The new pensantries: struggles for autonomy and sustainability in an era of empire and globalization, Ploeg (2008) afirma que, nas formas de utilização dos recursos, o distanciamento ou a aproximação com os mercados tendem a variar

16. Em sua obra Agricultural market economics: a neoinstitutional analysis of the exchange, circulation and distribution of agricultural products, de 1998, Vitto Saccomandi aponta que na agricultura familiar surgem experiências que constroem trajetórias na perspectiva do crescimento com elevado uso de recursos externos e forte aproximação do mercado monopolista (com um grau maior de dependência); e outras a partir do desenvolvimento endógeno e com certo distanciamento do mercado monopolista (buscando relativa autonomia). na mesma proporção dos graus diferenciados de produção econômica da agricultura familiar. Quanto aos territórios Açu-Mossoró e Sertão do Apodi (RN), é necessário considerar, nessa aproximação ou distanciamento, o padrão técnico, assim como o papel da intensificação da força de trabalho familiar. Esta intensificação é o que Ploeg (2008) define como labour-driven intensification ${ }^{17}$, o que faz a agricultura familiar se estruturar e contribuir para a inclusão produtiva, a partir de práticas e ações em nível micro baseadas na organização coletiva, na agregação de valor e no acesso a bons mercados.

O foco dessa estratégia se concentra na criação de oportunidades de inclusão produtiva para cada vez mais pessoas e, para Ploeg et al. (2004), se encaixa no ambiente da agricultura familiar por esta se apresentar como ambiente fértil para o surgimento de novidades (novelty production) e de inovações (innovation production). Esse é um approach que se apresenta adequado para a dinamização econômica nos territórios via ações do Proinf, assim como para o que Santos Junior e Waquil (2012) constataram no estado de Santa Catarina, região Sul do Brasil, quando estudaram a influência de fatores econômicos, institucionais e sociais na inserção de agroindústrias rurais. É a estrutura econômica que faz aflorar empreendimentos e técnicas novas de produção, os quais podem se tornar aquilo que Ploeg et al. (2004) denomina seeds of transition ${ }^{18}$. Segundo Ploeg et

17. Para Ploeg (2008), essa intensificação, ou labour-driven intensification, implica em constante acréscimo na produção, devido a um maior rendimento por objeto de trabalho. Do ponto de vista técnico, esse rendimento aumenta com o uso crescente de insumos e fatores de produção por objeto de trabalho, ou eficiência técnica melhorada. Neste sentido, a chave para rendimentos crescentes é a quantidade e a qualidade de trabalho.

18. Para Ploeg et al. (2004), a agricultura é constantemente confrontada com mudanças de expectativas e demandas sociais relativas ao seu papel de produção de alimentos. Cumprindo com essas expectativas e demandas exigirá uma abrangente, de longo alcance e, portanto, longe de transição fácil e duradouro da agricultura. Este livro procura explorar as sementes dessa transição pela descrever e analisar a produção de novidades promissoras (ou seja, novos modos sustentáveis de fazer e pensar) em relação ao regime dominante (ou seja, o modo efetivo e institucionalizado de fazer e pensar). 
al. (2004), as novidades e as inovações possuem trajetórias diferentes, pois enquanto as inovações seriam exógenas e definidas como padrão, externas e globalizadas, as novidades seriam endógenas, diversificadas e se caracterizariam pela contextualização, pela internalização e pela territorialização (OOSTINDIE e BROEKHUIZEN, 2008; PLOEG et al. 2004; BRUNORI, 2009).

A contextualização diz respeito às condições através das quais os agricultores adquirem o conhecimento para gerar as novidades no âmbito econômico, social e institucional em que estão inseridos e enraizados. Na maioria das vezes, as novidades e as inovações são o resultado da "fusão de horizontes" entre o mundo dos agricultores, em que predomina o contato com a natureza e o uso do conhecimento natural, com "mundos" de cientistas, ambientalistas, consumidores etc., em que predomina o conhecimento científico (STUIVER et al., 2004). A internalização refere-se à dinâmica endógena desenvolvida a partir da base de recursos que sustenta a produção das novidades ${ }^{19}$, em que predomina o uso de recursos internos, dinâmica que acontece em uma região ou unidade de produção. Isso faz com que as novidades sejam mais eficientes, pois através de rearranjos no uso dos recursos conseguem aumentar a produção e baixar os custos da atividade agrícola. E a territorialização envolve a ideia de que as novidades nascem de um local ou de um território, e o seu surgimento depende do tempo, do aprendizado, do meio ambiente e da cultura em que o trabalho na agricultura está inserido. Atualmente, segundo Perico (2009, p. 24), os governos buscam empreender trajetórias bem-sucedidas com o intuito de melhorar a qualidade do gasto público e gerar inclusão produtiva.

19. Novidades e/ou inovações que podem surgir no ambiente da agricultura familiar dizem respeito à legalização de produtos agrícolas processados. Como exemplo, podem ser destacados o Serviço de Inspeção Federal (SIF), o Serviço de Inspeção Estadual (SIE), o Serviço de Inspeção Municipal (SIM) e a legislação para a produção da polpa de frutas, como a Lei n. 8.918/95, que dispõe sobre a padronização, o registro, a inspeção, a produção e a fiscalização de bebidas, e que autoriza a criação da Comissão Intersetorial de Bebidas (BRASIL, 1995).
Para Nunes et al. (2014), apesar das suas limitações, o Proinf se configura como um dos mais importantes instrumentos de financiamento da política de desenvolvimento territorial, visando a estruturação da produção econômica da agricultura familiar discutida de forma participativa pelos Colegiados Territoriais. No entanto, uma deficiente articulação institucional e um frágil processo de gestão social nos territórios AçuMossoró e Sertão do Apodi (RN) desde 2003 até 2013 têm gerado as limitações na implantação e governança, o que levou a SDT a financiar ações de monitoramento e avaliação ${ }^{20}$ para os projetos financiados e definir critérios. A partir de 2010, os projetos para construção, ampliação ou recuperação de obras físicas foram condicionados aos seguintes requisitos, conforme o Proinf (2012): a) todos os contratos de obras na área do território firmados com a SDT/MDA até o exercício de 2010, no âmbito do Proinf, têm de estar concluídos ou em execução; b) as obras já concluídas devem estar em funcionamento e c) a proposta a ser apresentada tem que contemplar a totalidade da obra para o seu funcionamento, bem como as máquinas e equipamentos.

Os recursos de capital são aplicados para a estruturação de entidades privadas, e os projetos poderão ainda ser de transferência voluntária ou obrigatória, conforme art. 25 da Lei Complementar n. 101, de 04 de maio de 2000. A Lei n. 12.249, de 11 de junho de 2010, permite aos órgãos do governo federal operar os recursos na modalidade de transferências obrigatórias para os municípios com menos de 50 mil habitantes que integram o Programa Territórios da Cidadania (PTC), por intermédio de termos de compromisso, conforme artigos 104 a 106 da referida lei, mediante regulamentação anual através de decreto presidencial (PROINF, 2012).

20. Com as Células de Acompanhamento e Informação (CAIs), as universidades, em uma parceria com a SDT/ $\mathrm{MDA} / \mathrm{CNPq}$, realizaram trabalhos de coleta, registro e análise de informações sobre os territórios da cidadania, além de apoiar a gestão dos colegiados em 27 projetos que atendem aos 37 territórios espalhados em 607 municípios brasileiros. Os trabalhos começaram em agosto de 2010 e se estenderam até agosto de 2013. 
Cabe ainda ressaltar as seguintes normas: Lei n. 4.320, de 17 de março de 1964; Lei Complementar n. 101/2000; e Lei de Diretrizes Orçamentárias (LDO) de cada exercício orçamentário, que regula a execução dos recursos previstos anualmente no Orçamento Geral da União, além da Portaria Interministerial 507/2011. Com base no manual do Proinf (2012), para que um projeto seja aprovado pelo Colegiado Territorial e financiado pela SDT, devem ser atendidas as seguintes exigências: a) ser de interesse público; b) ter sua aplicação em patrimônio público, ou seja, o investimento deve ser feito em área pública; c) a posse, manutenção e conservação dos bens devem ser de responsabilidade do proponente; d) pode ser considerada a implantação de infraestrutura para apoio à prestação de serviços para a agricultura familiar pelo proponente e e) o proponente envia o projeto e pode realizar a gestão compartilhada com os beneficiários, definindo as obrigações e o funcionamento das estruturas na forma da lei, em especial, obedecendo ao art. 63 da Portaria 507/2011.

No entanto, apesar desse marco legal, não foram construídas estruturas de governança capazes de possibilitar uma eficiente gestão social, o que, de acordo com Nunes et al. (2014), gera questionamentos sobre o papel institucional do Colegiado Territorial nas ações de inclusão produtiva que visam à dinamização econômica dos territórios por meio da implantação dos projetos financiados pelo Proinf. Tal afirmativa se justifica ao ser revelada a situação da estrutura econômica financiada pelo referido programa e construída nos territórios Açu-Mossoró e Sertão do Apodi (RN) de 2003 até 2013, que, como será mostrado no item 4 , jamais funcionou.

\section{Metodologia}

A coordenação da política de desenvolvimento territorial é realizada pela Secretaria de Desenvolvimento Territorial do Ministério do Desenvolvimento Agrário (SDT/MDA), a qual, visando facilitar a gestão territorial, tem desenvolvido mecanismos para monitoramento e avalia- ções que ajudem na qualidade dos investimentos por meio das políticas públicas. Um destes mecanismos é o Sistema de Gestão Estratégica (SGE), um banco de dados que vem criando instrumentos para a coleta de dados com o propósito de definir indicadores de desenvolvimento. Para a pesquisa do Proinf, foi utilizado o Questionário de Avaliação de Projetos de Investimento (Q5). Com base no documento de referência, que é o Manual para Avaliação de Projetos de Investimento, as estruturas de produção econômica da agricultura familiar constituem condições e recursos disponíveis às organizativas coletivas dos territórios da cidadania (cooperativas, associações, redes etc.), sendo indispensável a gestão social das políticas públicas para a execução e êxito dos projetos de estruturação econômica.

Para situar o ambiente do estudo, como mostra a Figura 1, tem destaque para os dois territórios do Rio Grande do Norte, onde, de acordo com o PTDRS (2010), o Território Açu-Mossoró abrange uma área de $7.974 \mathrm{~km}^{2}$, sendo composto por 14 municípios, a saber: Alto do Rodrigues, Areia Branca, Assú, Baraúna, Carnaubais, Grossos, Ipanguaçu, Itajá, Mossoró, Pendências, Porto do Mangue, São Rafael, Serra do Mel e Tibau. Já o Território Sertão do Apodi abrange uma área de $8.280,20 \mathrm{~km}^{2}$, composto por 17 municípios: Apodi, Campo Grande, Itaú, Janduís, Rodolfo Fernandes, Umarizal, Caraúbas, Felipe Guerra, Governador Dix-Sept Rosado, Messias Targino, Olho-d'água do Borges, Paraú, Patu, Rafael Godeiro, Severiano Melo, Triunfo Potiguar e Upanema.

Como procedimento metodológico, foi realizada coleta de dados primários com a aplicação de questionários a um representante de cada instituição proponente dos projetos Proinf, além de um membro, por território, do colegiado territorial. Como estratégia de coletas de dados foram realizadas visitas in loco às construções e obras já iniciadas, em andamento ou paralisadas, com o objetivo de obter informações acerca dos projetos de infraestrutura definidos nos Planos Territoriais de Desenvolvimento Rural Sustentável (PTDRS) e priorizados pelos territórios Açu-Mossoró e Sertão do Apodi. 
538 - Dinamização Econômica e Agricultura Familiar: limites e desafios do apoio a Projetos de Infraestrutura (Proinf) em territórios rurais do Nordeste

Figura 1. Mapas dos territórios da cidadania Açu-Mossoró e Sertão do Apodi (RN)
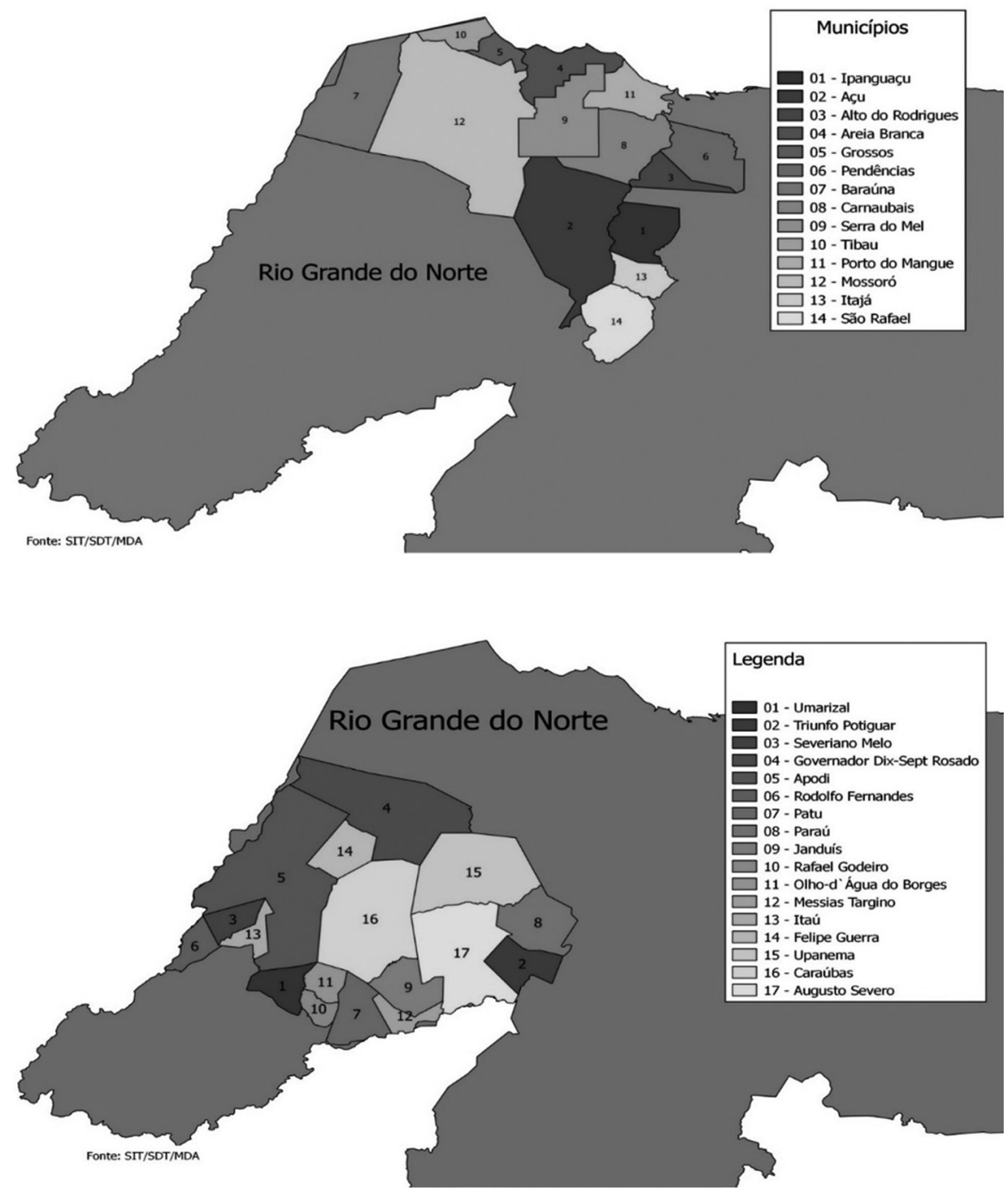

Fonte: SIT, SDT, MDA. Elaborado pelos autores, 2015.

A metodologia foi desenvolvida para todos os territórios do País pela Secretaria de Desenvolvimento Territorial (SDT), como mostrado no Quadro 1, e a coleta dos dados é realizada a partir do Questionário de Avaliação de Projetos de Investimento (Q5). Este questionário é composto por 62 perguntas, em que, além das nove primeiras que correspondem à identificação da entrevista, há 22 que correspondem ao planejamento do projeto, 14, à execução e 17, à avaliação dos indícios de impactos do projeto. 


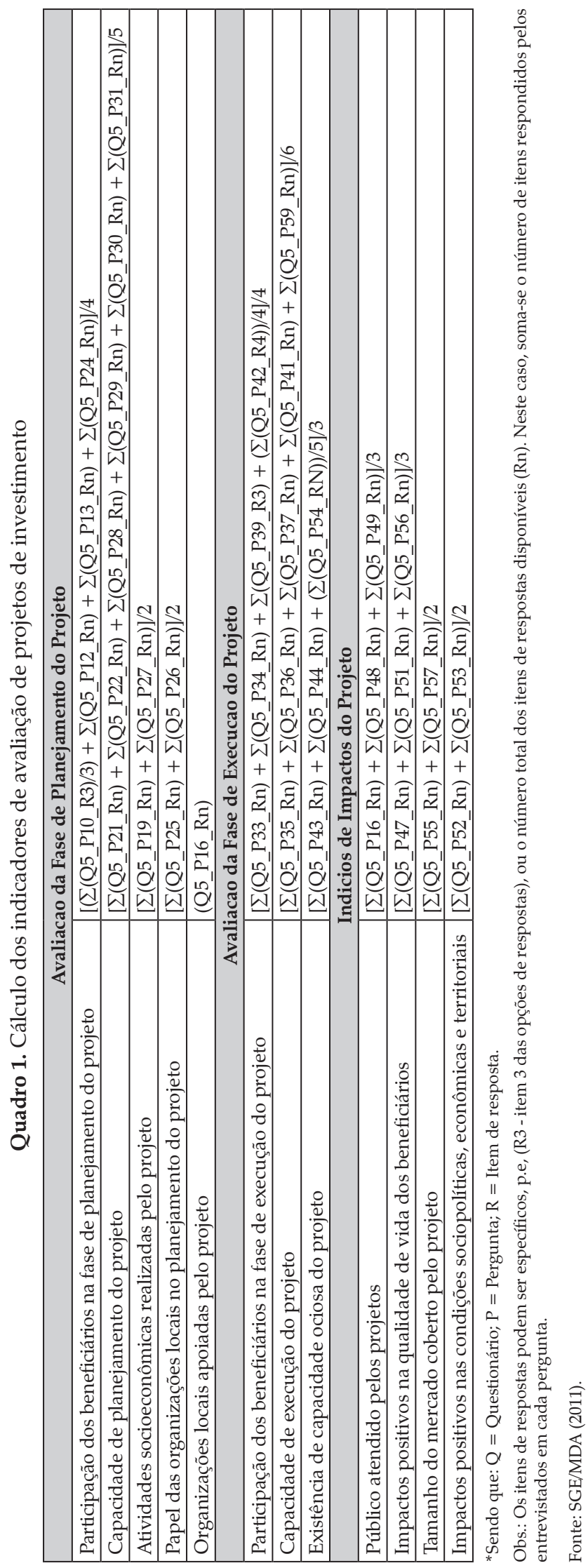


As visitas se realizaram de outubro a dezembro de 2012 e de outubro a dezembro de 2013, tendo sido aplicados 18 questionários a representantes das entidades proponentes de projetos Proinf, aos membros do Colegiado e aos beneficiários dos projetos. A pesquisa teve como foco os projetos que se encontram concluídos e/ou com obras paralisadas. No território AçuMossoró, foram aplicados três questionários com representantes de instituições proponentes, três com membros do Colegiado e três com beneficiários distribuídos nos municípios de Alto do Rodrigues, Mossoró, Ipanguaçu, Açu e Serra do Mel. No Território Sertão do Apodi, foram aplicados três questionários com representantes das instituições proponentes dos projetos Proinf, três questionários com membros do Colegiado e três com beneficiários, distribuídos nos municípios de Umarizal, Upanema, Apodi e Janduís. Os questionários foram elaborados por critérios definidos pela equipe técnica da SDT/MDA, e a metodologia foi desenvolvida para ser aplicada em todos os territórios da cidadania do País.

Os questionários elaborados pela SDT/MDA eram estruturados a partir de questões fechadas; no entanto, foram realizadas anotações em espaços abertos de comentários e inquietações dos atores, tanto da sociedade civil como do Poder Público, sobre o desempenho do Proinf nos dois territórios estudados. Essas anotações serviram de base para análise dos dados da pesquisa, a partir falas dos envolvidos no processo de desenvolvimento territorial.

\section{Resultados e discussão: os projetos de infraestrutura territorial (Proinf) nos territórios Açu-Mossoró e Sertão do Apodi (RN)}

O Rio Grande do Norte encontra-se dividido em dez territórios de identidade, denominados pela SDT/MDA Territórios Rurais e da Cidadania, sendo que, no período deste estudo, apenas três se encontravam inseridos na política como Territórios da Cidadania: Sertão do Apodi,
Açu-Mossoró e Mato Grande. Os demais ainda configuravam-se como territórios rurais (PTDRS, 2010). Com vistas ao desenvolvimento de atividades econômicas tradicionais, a exemplo da fruticultura irrigada, bovinocultura, ovinocaprinocultura, cajucultura, apicultura, piscicultura, entre outras, organizações coletivas da agricultura familiar têm demandado cada vez mais estruturas de produção para a agregação de valor, buscando engendrar uma lógica de desenvolvimento endógeno nos territórios. Para tanto, representantes dessas organizações têm buscado participar das discussões do Pronat realizadas nos Colegiados Territoriais.

Com isso, nos últimos dez anos, os investimentos da SDT/MDA nos territórios Açu-Mossoró e Sertão do Apodi (RN), por meio do Proinf, têm sido direcionados especialmente para a construção de estruturas de beneficiamento de produtos agrícolas, como forma de estimular o surgimento de agroindústrias no âmbito das cadeias produtivas de base familiar já priorizadas nos debates e nos planos de desenvolvimento territorial.

A maior parte dos projetos elaborados, votados e deliberados pelos Colegiados Territoriais foi para a compra de equipamentos destinados à comercialização em feiras da agricultura familiar e para unidades de beneficiamento, como usinas de leite, entrepostos de mel, unidades de beneficiamento de pescado e os custeios para fomentar a política territorial executada por meio de ONGs com atuação Territorial. Do ponto de vista da política territorial, essa ação do Proinf tenderia para um inquestionável processo de estruturação da agricultura familiar e contribuiria com a dinamização econômica dos territórios Açu-Mossoró e Sertão do Apodi (RN), possibilitando a inclusão produtiva. Considerando a carência de ações de inclusão produtiva, especialmente numa região como o Nordeste, isso ocorreria com a tão necessária criação de oportunidades, através da estratégia labour-driven intensification, no âmbito do território. Estas oportunidades devem ser baseadas na organização coletiva, na agregação de valor e no acesso a mercados, além de tornar o ambiente favorável ao surgimento de novidades 
(novelty production) e de inovações (innovation production).

No entanto, quanto ao processo de avaliação de projetos financiados pelo Proinf que contempla informações para o planejamento e a execução, incluindo a implantação e o gerenciamento das atividades dos empreendimentos em funcionamento e os indícios de impacto econômicos e socioculturais, os indicadores da pesquisa mostraram um cenário diferente nos dois territórios estudados. Considerando-se que a avaliação de cada um dos indicadores calculados varia entre 0 (zero) e 1, sendo 1 a melhor avaliação e 0 (zero) a pior avaliação, como mostra a Figura 2, a fase de planejamento no Território Açu-Mossoró, que engloba a definição da área de intervenção, diagnóstico e formulação de propostas, teve como indicador 0,347 (ruim). A fase de execução que se preocupa em identificar as ações e garantir uma boa gestão do projeto alcançou 0,423 (regular). Os indícios de impacto, que identificam a abrangência dos resultados, atividades promovidas e nível de funcionamento do projeto, alcançaram o nível mais baixo, 0,207 (ruim). E, por último, a gestão do projeto, que compreende o gerenciamento dos empreendimentos e a comparação entre os resultados previstos e alcançados por eles ficou com 0,335 (ruim).

Nota-se, portanto, que tanto a fase de planejamento, os indicadores de gestão, quanto os indícios de impacto estão na faixa ruim do cálculo, demonstrando uma deficiência em momentos fundamentais para o êxito de qualquer empreendimento. Esse resultado da pesquisa de avaliação de projetos de investimento do Proinf para o Território Açu-Mossoró sinaliza a reprodução de receitas antigas, a exemplo dos projetos implantados em períodos anteriores pelo Pronaf

Figura 2. Avaliação de projetos de investimento do Território Açu-Mossoró-RN

1. Planejamento

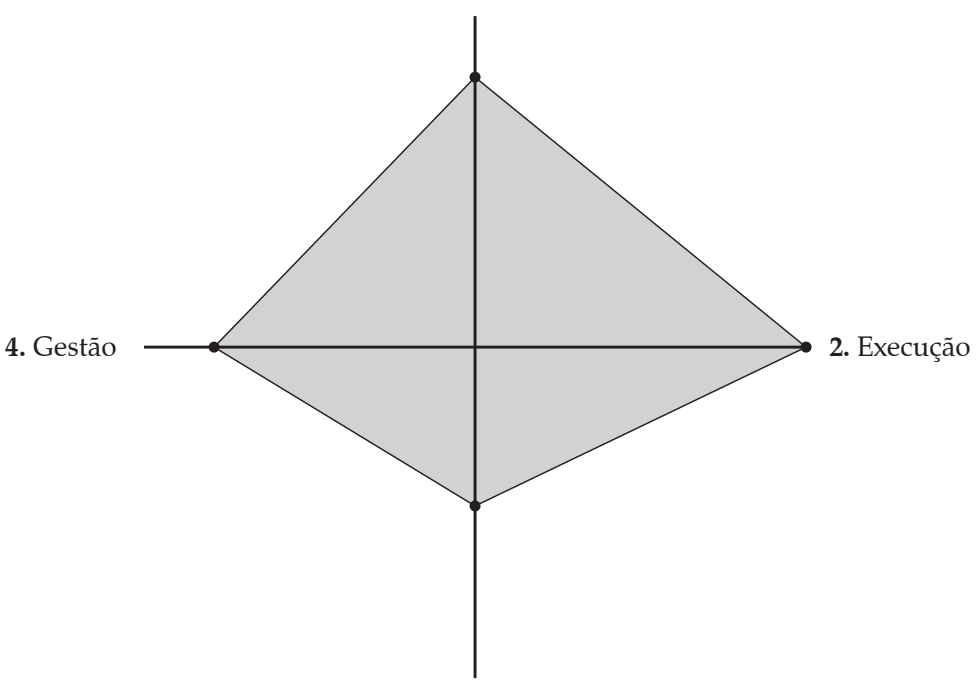

3. Indícios de impacto

\begin{tabular}{|l|l|}
\hline \multicolumn{2}{|c|}{ Quadro de Indicadores } \\
\hline 1. Avaliação da fase de planejamento do projeto & 0,347 \\
\hline 2. Avaliação da fase de execução do projeto & 0,423 \\
\hline 3. Indícios de impacto & 0,207 \\
\hline 4. Indicadores gerais de gestão do projeto & 0,335 \\
\hline
\end{tabular}

Legenda: 0,00 - 0,20 = Crítico; 0,20 - 0,40= Ruim; 0,40 - 0,60= Regular; 0,60 - 0,80= Bom; $0,80-1,00=$ Ótimo.

Fonte: SGE/MDA (2011). 
542 - Dinamização Econômica e Agricultura Familiar: limites e desafios do apoio a Projetos de Infraestrutura (Proinf) em territórios rurais do Nordeste

Infraestrutura via CMDRs, muitas vezes sem a participação efetiva da sociedade e com decisão predominante dos gestores públicos. No caso do Proinf, na metodologia do arranjo institucional ficam claras as decisões que serão tomadas pelos Colegiados Territoriais, os quais recebem a sugestão para uma constituição paritária, ou seja, 50\% de integrantes do poder público e $50 \%$ da sociedade civil.

No entanto, a pesquisa mostra que essa paridade passa a não mais existir no momento em que a participação no processo de discussão, de elaboração e deliberação dos projetos nos Colegiados Territoriais dos dois territórios é ditada pela sociedade civil; porém, a contratação e a implantação dos projetos de infraestrutura econômica são ditadas e realizadas pelos gestores públicos por meio de convênios entre os entes federativos. Neste contexto, os contratos são executados apenas pelos proponentes (prefeituras ou órgãos estaduais), muitas vezes sem sequer conhecerem os conteúdos dos projetos, limitando-se aos governos estaduais e municipais e sem muita diferença do arranjo institucional dos CMDRs dos anos 1990.

Para se ter uma ideia, na realização das entrevistas com os representantes do poder público, foram recorrentes os comentários sobre a falta de conhecimento do projeto, a exemplo do comentário do gestor público de um município proponente:

[...] a falta de contrapartida do Estado e/ou dos municípios e a falta de diálogo, de mais conversa entre o MDA, o Colegiado Territorial e com as proponentes dificultaram muito as coisas nesses anos todos, sendo também perceptível o reflexo da ausência da participação da Secretaria da Agricultura do Estado e das prefeituras na construção das propostas dos projetos do Proinf. É possível perceber ainda a fragilidade no arranjo institucional do Colegiado Territorial, faltando, a nosso ver, a concertação social no tocante à infraestrutura produtiva (Prefeito de Alto do Rodrigues-RN).

Quanto aos projetos, a pesquisa oportunizou uma análise daqueles priorizados e elaborados por meio do Colegiado Territorial. Quando se analisa a infraestrutura territorial para a agricultura familiar financiada pelo MDA, o cenário é preocupante, pois nos 10 anos de execução do Proinf os territórios estudados não apresentaram mudanças quanto às estruturas econômicas, e menos ainda no que diz respeito ao surgimento de novidades (novelty production) ou de inovação (innovation production) para a agregação de valor e legalização dos produtos. No Território Açu-Mossoró, destaca-se o projeto da usina de beneficiamento de leite, pois, apesar da necessidade dos agricultores que produzem leite na região, a prefeitura não conseguiu concluir e entregar oficialmente a obra; a cooperativa que deveria ser constituída para ser responsável pela gestão da agroindústria, articulação da produção e diálogo com os gestores municipais e com o Ministério da Agricultura e Pecuária (Mapa) ainda não está em funcionamento.

A pesquisa revelou, ainda, que de acordo com a fala de um dos atores envolvidos representando a sociedade civil, a deficiência do arranjo institucional do colegiado no sentido de realizar ações devido à fragilidade institucional e de estrutura econômica e social dos próprios territórios se dá por vários motivos. Entre eles está a ausência de indústrias que produzam e comercializem equipamentos, e a carência de profissionais com conhecimento no processo de implantação de agroindústrias. Para este ator da Sociedade Civil:

[...] a falta de técnicos em agroindústria no planejamento e elaboração, falta de empresas na região que forneça os equipamentos, falta de articulação política e a fragilidade na organização dos agricultores foram os principais problemas no decorrer dos anos (J. S. T. Técnico do município de Mossoró-RN, representante da Sociedade Civil).

De 2003 a 2013, o Território Açu-Mossoró aprovou 18 projetos do Proinf, sendo que 13 ficaram nos municípios do Vale do Açu, quais sejam: Açu, Alto do Rodrigues, Carnaubais, Ipanguaçu, São Rafael e Pendências; já na área de influência de Mossoró constam cinco projetos nos municípios de Serra do Mel e Mossoró. Entre 2005 e 
2013, os investimentos no Território Açu-Mossoró totalizaram $\mathrm{R} \$ 3.084 .093,18$ (ver Quadro 2). No Território Açu-Mossoró, o encaminhamento das propostas de estruturação econômica ocorreu através da cooperação com a Secretaria de Estado da Agricultura, Pecuária e da Pesca (Sape/RN) e com algumas prefeituras municipais.

Conforme o manual do Proinf (2012), os projetos de estruturação econômica para os territórios da cidadania deverão beneficiar apenas os agricultores familiares, e somente órgãos da administração pública municipal, estadual e do Distrito Federal, além dos Consórcios Públicos, poderão ser proponentes e encaminhar as propostas para financiamento. Daí a necessidade de envolver gestores municipais (prefeitos) e estadu- ais para que participem da concepção e da elaboração, pois os projetos serão inseridos no Sistema de Convênios do Governo Federal (Siconvi) pelas prefeituras ou órgãos estaduais. Isso porque os proponentes (municipais e/ou estaduais) são os responsáveis pela contratação junto à Caixa Econômica Federal, que atua como agente financeiro e mandatário da União para disponibilizar os recursos, bem como pela execução dos projetos de estruturação econômica.

No entanto, muitas vezes os projetos de infraestrutura apoiados pelo Proinf foram discutidos e definidos, e o seu planejamento efetuado no âmbito do Colegiado Territorial sem a participação ou contato com os gestores públicos e com a Caixa Econômica Federal. Somente depois de

Quadro 2. Projetos de infraestrutura no Território Açu-Mossoró de 2003 a 2013

\begin{tabular}{|c|c|c|c|c|}
\hline Proponente & Ano & Descrição & Situação & R\$ MDA \\
\hline \multirow{4}{*}{$\begin{array}{l}\text { Prefeitura de Alto do } \\
\text { Rodrigues/RN }\end{array}$} & 2005 & 1 Miniusina de beneficiamento de leite. & Atrasada & $187.550,00$ \\
\hline & 2006 & 1 Veículo utilitário com baú isotérmico. & Concluída & $132.020,43$ \\
\hline & 2007 & Fortalecimento da cadeia produtiva do leite. & Concluída & $188.000,00$ \\
\hline & 2008 & $\begin{array}{l}\text { 1 Auditório na Miniusina com móveis, equipamentos e utensí- } \\
\text { lios Alto do Rodrigues. }\end{array}$ & Não Iniciada & $99.000,00$ \\
\hline \multirow[t]{3}{*}{$\begin{array}{l}\text { Prefeitura de Mossoró/ } \\
\text { RN }\end{array}$} & 2006 & $\begin{array}{l}\text { Construção e equipamento para grupos de Assentamento de } \\
\text { Reforma Agrária. }\end{array}$ & Paralisada & $127.000,00$ \\
\hline & 2007 & $\begin{array}{l}1 \text { Central de Comercialização da Agricultura Familiar de Mos- } \\
\text { soró (RN). }\end{array}$ & Não Iniciada & $150.000,00$ \\
\hline & 2009 & $\begin{array}{l}\text { Ampliação da Central de Comercialização da Agricultura Fa- } \\
\text { miliar de Mossoró (RN). }\end{array}$ & Não Iniciada & $374.924,75$ \\
\hline \multirow[t]{2}{*}{$\begin{array}{l}\text { Prefeitura de Ipangua- } \\
\text { çu/RN }\end{array}$} & 2008 & $\begin{array}{l}\text { 1 Miniusina para beneficiamento de produtos da Carnaubeira } \\
\text { de Ipanguaçu (RN). }\end{array}$ & Atrasada & $99.750,00$ \\
\hline & 2009 & 1 Unidade didática de processamento de carne. & Não iniciada & $363.971,07$ \\
\hline \multirow[t]{2}{*}{ Prefeitura de Assu/RN } & 2009 & $\begin{array}{l}1 \text { Parque de exposição de Animais da agricultura familiar do } \\
\text { vale do Assu. }\end{array}$ & Não iniciada & $195.000,00$ \\
\hline & 2010 & $\begin{array}{l}\text { Ampliação do parque de exposição de animais no município } \\
\text { de Assu. }\end{array}$ & Não iniciada & $200.000,00$ \\
\hline $\begin{array}{l}\text { Prefeitura de Pendências/ } \\
\text { RN }\end{array}$ & 2009 & 1 Usina de beneficiamento de pescados de Pendências. & Não iniciada & $126.750,00$ \\
\hline $\begin{array}{l}\text { Prefeitura de Carnaubais/ } \\
\text { RN }\end{array}$ & 2010 & 1 Centro de Comercialização de animais de pequeno porte. & Não iniciada & $100.000,00$ \\
\hline $\begin{array}{l}\text { Secretaria Estadual da } \\
\text { Agricultura Sape/RN }\end{array}$ & 2008 & $\begin{array}{l}\text { Complementação da miniusina de beneficiamento de leite de } \\
\text { Alto do Rodrigues. }\end{array}$ & Não iniciada & $175.112,00$ \\
\hline Emater/RN & 2010 & $\begin{array}{l}\text { Máquinas e equipamentos para entreposto de mel de Serra do } \\
\text { Mel. }\end{array}$ & Não iniciada & $409.536,00$ \\
\hline \multirow{3}{*}{$\begin{array}{l}\text { Secretaria Estadual da } \\
\text { Agricultura Sape/RN }\end{array}$} & 2011 & Ipanguaçu: equipamentos. & Não contratada & $189.000,00$ \\
\hline & 2012 & Ipanguaçu: equipamentos. & Não contratada & $259.000,00$ \\
\hline & 2013 & $\begin{array}{l}\text { Ipanguaçu e Pendências: apoio à central de beneficiamento da } \\
\text { palha da carnaúba (Ipanguaçu), caminhão baú (Pendências). }\end{array}$ & Não contratada & $259.000,00$ \\
\hline \multicolumn{4}{|l|}{ Total geral } & $3.084 .093,18$ \\
\hline
\end{tabular}

Fonte: Banco de dados Facem/UERN. Pesquisa de campo (2013). 
votados e deliberados é que os proponentes e a Caixa Econômica Federal eram procurados pelo Colegiado para encaminhar os projetos através do Siconvi para, a partir disso, iniciar o processo de execução dos projetos. Porém, sem uma eficiente articulação do Colegiado com os proponentes e com a Caixa Econômica Federal, a gestão social se tornou impraticável, fazendo com que a inclusão produtiva não acontecesse, a ponto de não gerar sequer a contratação de quase todos os projetos. Cabe destacar, nesse arranjo institucional, que enquanto os projetos de estrutura econômica do Proinf são conveniados através do poder público, os recursos de custeio sempre foram executados pela sociedade civil.

Neste contexto, considerando que a avaliação de cada um dos indicadores calculados varia entre 0 (zero) e 1 , sendo o valor 1 a melhor avaliação e 0 (zero), a pior avaliação, no Território Sertão do Apodi, como mostra a Figura 3, a fase de planejamento alcançou o melhor indicador 0,416 (regular). A fase de execução alcançou 0,289 (ruim). Já os indícios de impacto alcançaram o nível mais baixo, ou seja, 0,116 (crítico). Por último, a gestão do projeto ficou com 0,325 (ruim).

Neste caso, percebe-se que na fase de planejamento o indicador foi bem melhor do que no Território Açu-Mossoró. Entretanto, o indicador de gestão ficou na faixa ruim do cálculo, e os indícios de impacto ficaram no nível crítico, o que demonstra, assim como no Território Açu-Mossoró, uma deficiência em fases essenciais para o êxito de qualquer projeto econômico. Esse resultado da pesquisa de avaliação de projetos de investimento do Proinf para o Território Sertão do Apodi também indica a fragilidade no arranjo institucional e no

Figura 3. Avaliação de Projetos de Investimento do Território Sertão do Apodi-RN

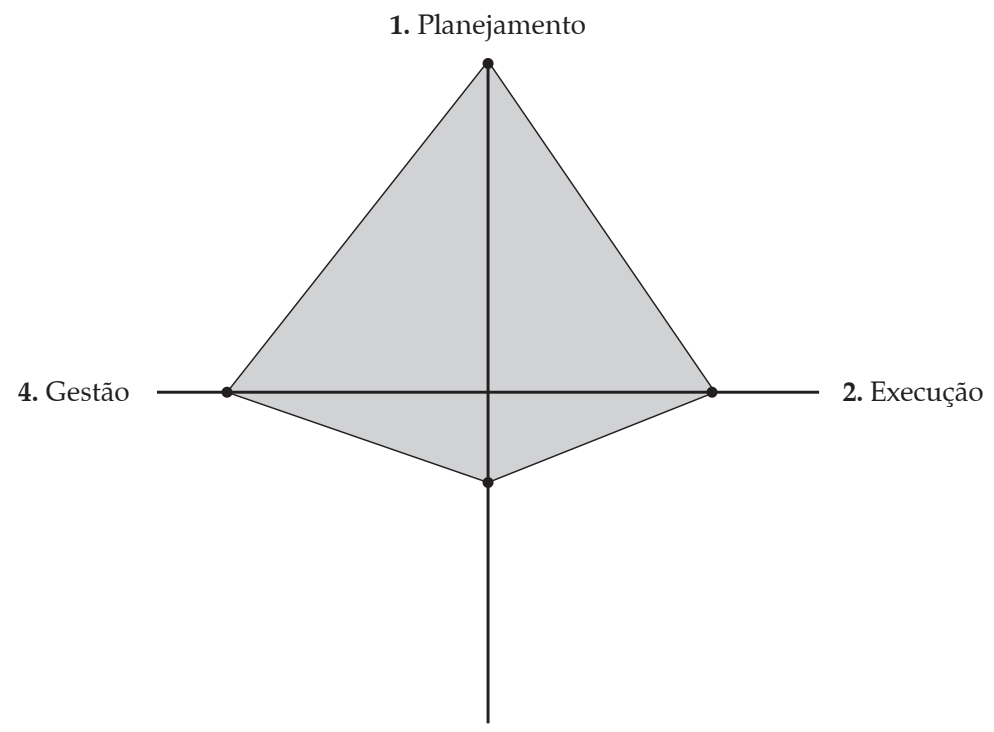

3. Indícios de impacto

Quadro de Indicadores

\begin{tabular}{|l|c|}
\hline \multicolumn{2}{|c|}{ Quadro de Indicadores } \\
\hline 1. Avaliação da fase de planejamento do projeto & 0,416 \\
\hline 2. Avaliação da fase de execução do projeto & 0,289 \\
\hline 3. Indícios de impacto & 0,116 \\
\hline 4. Indicadores gerais de gestão do projeto & 0,325 \\
\hline
\end{tabular}

Legenda: 0,00 - 0,20 = Crítico; 0,20 - 0,40= Ruim; 0,40 - 0,60= Regular; 0,60 - 0,80= Bom; $0,80-1,00=$ Ótimo.

Fonte: SGE/MDA. 2011. 
diálogo, negociação e estabelecimento de consensos entre o poder público e a sociedade civil, em especial as representações de agricultores familiares no território. Nos dois territórios, a causa maior do não alcance dos resultados reside na deficiente abordagem coletiva do complexo arranjo institucional dos Colegiados Territoriais. Nos dois territórios pesquisados, existe uma ausência de participação dos gestores públicos (prefeitos), apesar de ser destes o poder de ditar a contratação e implantação da estruturação econômica, o que reflete nas deficiências da concepção, a elaboração e os conteúdos dos projetos, assim como na governança institucional e gestão social durante o processo de pactuação dos acordos.

Apesar de a ação normativa ser apresentar bem elaborada, a exemplo do Manual do Proinf, na prática não tem acontecido com a mesma perfeição. Existe um descompasso entre a SDT que financia e coordena a metodologia da política territorial, as instâncias dos Colegiados Territoriais que discutem, decidem e deliberam, as entidades proponentes (prefeituras e/ou órgãos estaduais), os elaboradores dos projetos (que muitas vezes não se sabe quem são), e o órgão de execução financeira, neste caso a Caixa Econômica Federal. Muitas vezes não existe qualquer diálogo entre estas instâncias, em nenhuma direção, o que compromete o desempenho da política territorial e, sem governança para gerar sintonia entre as partes, qualquer ação do Proinf se torna praticamente impossível de ser bem-sucedida.

O Território Sertão do Apodi aprovou, entre 2003 e 2013, 17 projetos de investimento com montante de $\mathrm{R} \$ 5.795 .982,57$. Os recursos foram distribuídos contemplando as áreas de recursos hídricos, como construção de barragens sucessivas ao longo dos rios Umari e Upanema; cadeias produtivas, com destaque para a apicultura (construção do entreposto de mel); bovinocultura (construção de uma unidade de beneficiamento de leite e tanques de resfriamento); e apoio à comercialização, com a proposição dos centros de comercialização (ver Quadro 3).

Quadro 3. Projetos de infraestrutura no território Sertão do Apodi de 2003 a 2013

\begin{tabular}{|c|c|c|c|c|}
\hline Proponente & Ano & Descrição & Situação & R\$ MDA \\
\hline \multirow[t]{4}{*}{$\begin{array}{l}\text { Secretaria Estadual da } \\
\text { Agricultura Sape/RN }\end{array}$} & 2003 & $\begin{array}{l}\text { Território: Construção de } 7 \text { Barragens sucessivas no rio Uma- } \\
\text { ri no trecho Umarizal/Apodi }\end{array}$ & 2 construídas & $2.819 .170,00$ \\
\hline & \multirow[t]{2}{*}{2006} & Construção de Barragens a partir do rio Upanema & Não iniciada & $385.000,00$ \\
\hline & & $\begin{array}{l}\text { Território: Equipamentos para as feiras agroecológicas da } \\
\text { rede Xique Xique nos Territórios Sertão do Apodi, }\end{array}$ & Concluída & $90.275,00$ \\
\hline & 2007 & $\begin{array}{l}\text { Apodi (RN): Construção de } 1 \text { Entreposto do Mel e Equipa- } \\
\text { mentos. }\end{array}$ & Atrasada & $424.783,00$ \\
\hline \multirow[t]{2}{*}{ Prefeitura de Janduís } & \multirow[t]{2}{*}{2008} & Janduís (RN): Construção de 1 Central de Comercialização; & Atrasada & \multirow[t]{2}{*}{$101.322,00$} \\
\hline & & Janduís (RN): Equipamentos e Posto de Resfriamento de Leite. & Atrasada & \\
\hline \multirow[t]{3}{*}{ Prefeitura de Apodi } & 2008 & Apodi (RN): Construção de 1 Central de Comercialização. & Não iniciada & $5.054,30$ \\
\hline & \multirow[t]{2}{*}{2009} & Apodi (RN): Compra de 3 veículos; & Concluída & \multirow[t]{2}{*}{$107.100,00$} \\
\hline & & $\begin{array}{l}\text { Apodi (RN): Compra de } 3 \text { Data show para estruturação das } \\
\text { Bases de Serviço de Apoio à Comercialização. }\end{array}$ & Concluída & \\
\hline Prefeitura de Umarizal & 2009 & $\begin{array}{l}\text { Umarizal (RN): Construção de } 1 \text { Unidade de Beneficiamento } \\
\text { de Leite }\end{array}$ & Atrasada & $621.096,00$ \\
\hline \multirow{4}{*}{$\begin{array}{l}\text { Secretaria Estadual da } \\
\text { Agricultura Sape/RN }\end{array}$} & \multirow[t]{3}{*}{2009} & Janduís (RN): Construção de 1 Central de Comercialização; & \multirow[t]{4}{*}{ Não iniciada } & \multirow[t]{4}{*}{$193.277,27$} \\
\hline & & Janduís (RN): Equipamentos e Posto de Resfriamento de Leite. & & \\
\hline & & Apodi (RN): Construção de 1 Central de Comercialização. & & \\
\hline & 2010 & Território: Implantação de Tanques de resfriamento de leite. & & \\
\hline \multirow{2}{*}{$\begin{array}{l}\text { Secretaria Estadual da } \\
\text { Agricultura Sape/RN }\end{array}$} & 2011 & Apodi (RN): Conclusão do Entreposto de Mel & Não contratada & $250.000,00$ \\
\hline & 2012 & Apodi (RN): Equipamento apícola & Não contratada & $250.000,00$ \\
\hline Coopapi & 2013 & Território: Apoio a suporte forrageiro & Não contratada & $250.000,00$ \\
\hline \multicolumn{4}{|l|}{ Total geral } & $5.795 .982,57$ \\
\hline
\end{tabular}

Fonte: Banco de dados Facem/UERN. Pesquisa de campo (2013). 
Figura 4. Situação dos projetos de infraestrutura nos territórios de 2003 a 2013

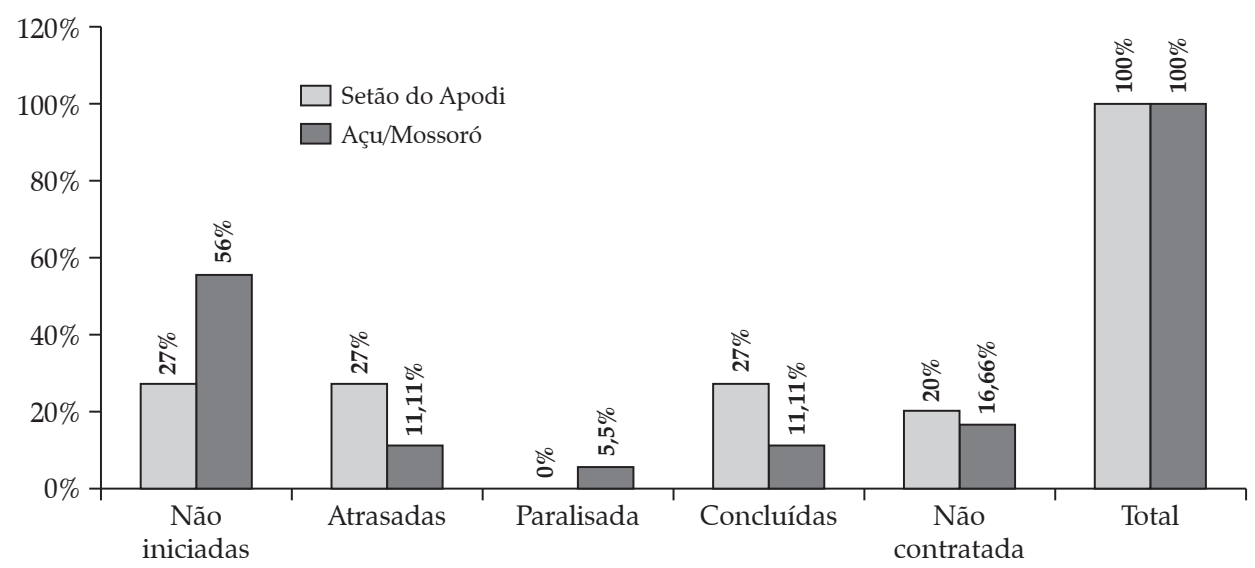

Fonte: Pesquisa de campo, 2013.

Dos 17 projetos, 10 tiveram como proponente a Sape/RN, e os sete restantes foram apresentados através das prefeituras de Apodi, Janduís e Umarizal. De todos os projetos, apenas duas barragens sucessivas, a aquisição dos veículos de apoio à comercialização e equipamentos para feiras agroecológicas da rede Xique $X_{i q u e}{ }^{21}$ foram implantados, enquanto o entreposto de mel e os demais não foram concluídos. A pesquisa revelou que uma das causas para a não implantação dos projetos ou sua não finalização nos prazos contratuais foi a falta de celeridade dos procedimentos para a conclusão dos contratos com os proponentes. Além disso, a falta de sensibilização dos gestores quanto à importância e prioridade dos projetos também contribuiu para o atraso dos projetos, devido a não liberação das contrapartidas, notas técnicas, licenciamento ambiental etc.

Cabe destacar que os territórios Açu-Mossoró e Sertão do Apodi têm iniciado a construção de uma significativa estrutura de organização social e produtiva a partir de suas cadeias produtivas. Entretanto, a dificuldade para disparar o processo de dinamização econômica reside na insu-

21. A rede Xique Xique, no Rio Grande do Norte, é uma experiência de diversificação da agricultura familiar (inspirada na Rede Ecovida de Agroecologia da região Sul do Brasil) que reúne a prática de uma agricultura sustentável baseada nos princípios da agroecologia com a ação coletiva via organizações da Economia Solidária. ficiência de estrutura de produção econômica, especialmente a destinada à agroindústria familiar que atenda aos padrões exigidos pelos órgãos de controle e de regulação. Um dos fatores que leva a esses resultados é a fragilidade do arranjo institucional e a falta de familiaridade dos proponentes com os projetos propostos e deliberados pelos Colegiados Territoriais, como mostra a Figura 4.

O cenário no Território Açu-Mossoró revela que $56 \%$ dos projetos aprovados através do Colegiado para infraestrutura sequer saíram do papel, enquanto que no Território Sertão do Apodi foram $27 \%$, praticamente a metade. As obras não contratadas, $16,66 \%$ e $20 \%$, respectivamente, e as com execução atrasada representam 11,11\% no Território Açu/Mossoró e 37\% no Sertão do Apodi, onde todos os projetos executados se limitam à aquisição de equipamentos, kits móveis (feiras) e veículos.

A pesquisa mostra a fragilidade da política territorial quanto à implantação de projetos de infraestrutura dos territórios por meio do Proinf. Quanto aos projetos concluídos, o território Sertão do Apodi obteve porcentagem maior, de $27 \%$, devido ao fato de terem sido apenas adquiridos equipamentos (veículos e Datashow por meio da prefeitura de Apodi) para as Bases de Serviços, e equipamentos para a instalação de feiras da agricultura familiar (barracas, balanças, 
monoblocos etc., por meio da Secretaria Estadual de Agricultura) destinados à rede Xique Xique. Já os 11,11\% do Território Açu-Mossoró foram da aquisição de apenas um caminhão refrigerado e um tanque para resfriamento de leite, por meio da prefeitura de Alto do Rodrigues (RN). Essa situação reflete, através da pesquisa, limitações mais para projetos de construção civil do que para a aquisição de equipamentos, sendo revelada uma deficiência e insuficiência do processo de estruturação econômica no âmbito das cadeias produtivas dos dois territórios. Neste caso, tem destaque para a falta de estrutura a produção e ausência de legalização (SIF, SIE e SIM) para o mel, a polpa de frutas, a castanha de caju, leite e derivados, entre outros produtos da agricultura familiar.

Considerando-se a análise de um quarto grupo de indicadores, os quais agregam resul- tados dos anteriores, ou seja, o planejamento, a execução e os indícios de impacto, este foca em quatro variáveis-chaves para a gestão territorial de projetos: participação, capacidade de gestão, público atendido e impactos positivos do projeto. Considerando-se que a avaliação de cada uma das variáveis calculadas varia entre 0 (zero) e 1 , sendo 1 a melhor avaliação e 0 (zero), a pior, no Território Açu-Mossoró, como mostra a Figura 5, a participação dos beneficiários na gestão do projeto alcançou o indicador 0,440 (regular); e a capacidade de gestão do projeto obteve 0,489 (regular). Por outro lado, a variação do perfil do público apoiado pelo projeto alcançou o nível mais baixo: 0,127 (crítico). Por último, os impactos positivos para o desenvolvimento territorial ficaram com 0,286 (ruim), sendo o segundo menor.

Figura 5. Indicadores gerais de gestão dos projetos do Território Açu-Mossoró Índice de participação dos beneficiários na gestão do projeto

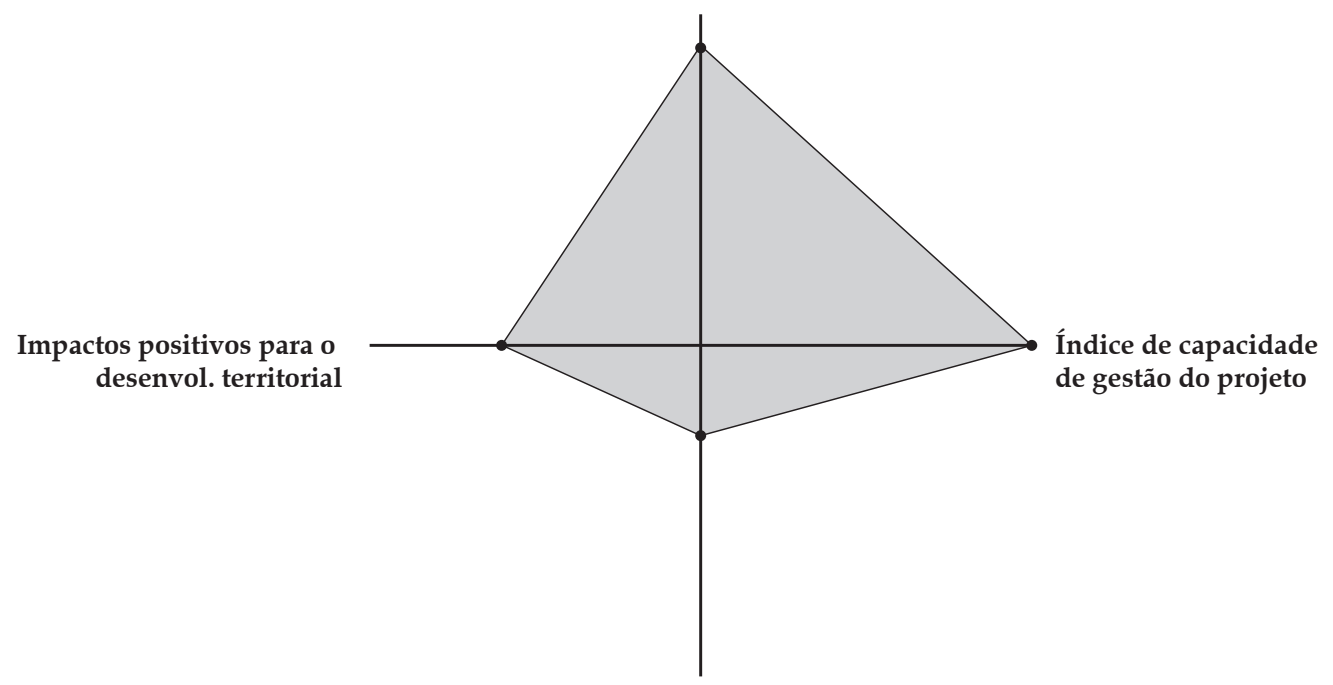

Índice de variação do perfil do público apoiado e atendido pelo projeto

\begin{tabular}{|l|l|}
\hline \multicolumn{1}{|c|}{ Indicadores Gerais de Gestão do Projeto } & $\mathbf{0 , 3 3 5}$ \\
\hline Índice de participação dos beneficiários na gestão do projeto & 0,440 \\
\hline Índice de capacidade de gestão do projeto & 0,489 \\
\hline Índice de variação do perfil do público apoiado pelo projeto & 0,127 \\
\hline Impactos positivos para o desenvolvimento territorial & 0,286 \\
\hline
\end{tabular}

Legenda: 0,00 - 0,20 = Crítico; 0,20 - 0,40= Ruim; 0,40 - 0,60= Regular; 0,60 - 0,80= Bom; $0,80-1,00=$ Ótimo.

Fonte: SGE/MDA (2011). 
Ao analisar este período de 10 anos, percebe-se que essas quatro variáveis destacam e afirmam profundas deficiências da política de desenvolvimento territorial no que diz respeito às ações do Proinf no Território Açu-Mossoró. A pesquisa mostra a relação entre a variação do perfil do público apoiado pelo projeto e os impactos positivos para o desenvolvimento territorial, em que os entrevistados externaram como sendo ruim e crítico o desempenho das ações de estruturação econômica para a agricultura familiar no Território Açu-Mossoró. No entanto, as variáveis que tratam da participação dos beneficiários na gestão do projeto e da capacidade de gestão do projeto tiveram, na percepção dos entrevistados, valores mais significativos do que as outras duas variáveis citadas acima.

Conforme mostra a Figura 6, no tocante ao Território Açu-Mossoró, a pesquisa revela que o principal motivo reside na má gestão do empreendimento (33\%), na falta de compromisso dos gestores $(11 \%)$ e na incapacidade técnica dos proponentes $(11 \%)$. Todavia, impressiona o percentual de entrevistados que não soube responder, revelando falta de conhecimento dos processos desenvolvidos no Território Açu-Mossoró, que pode indicar pouca divulgação ou ausência de transparência das ações implantadas pelas instituições e pelo Colegiado Territorial.
Ao serem verificados os motivos da não conclusão dos empreendimentos financiados pelo Proinf no Território Sertão do Apodi, a pesquisa mostrou que metade dos entrevistados acredita que a falta de compromisso dos gestores é o principal deles. A outra metade divide-se em má gestão da execução do empreendimento (25\%) e incapacidade técnica do proponente $(25 \%)$, sugerindo que os membros do Colegiado Territorial, gestores e beneficiários acreditam que os projetos não foram concluídos por problemas de gestão das entidades proponentes.

Cabe considerar que no, modus operandi da gestão dos projetos do Proinf nos territórios, o controle e a gestão dos recursos financeiros ficam sob a responsabilidade do proponente, conforme termo de cooperação para gestão compartilhada, envolvendo, ainda, outros órgãos estaduais e/ ou outras prefeituras locais que sediarem projetos. Neste arranjo institucional, proponente e Colegiado Territorial definirão os termos gerais a serem seguidos de uso e de manutenção da estrutura de produção econômica, e em cada município que sediar projetos financiados pelo Proinf deverá ser criada uma Comissão Permanente de Gestão, composta pelo proponente e pelos representantes dos agricultores familiares. O Colegiado Territorial, o proponente e o Conselho

Figura 6. Caso o empreendimento não esteja concluído, quais os motivos?

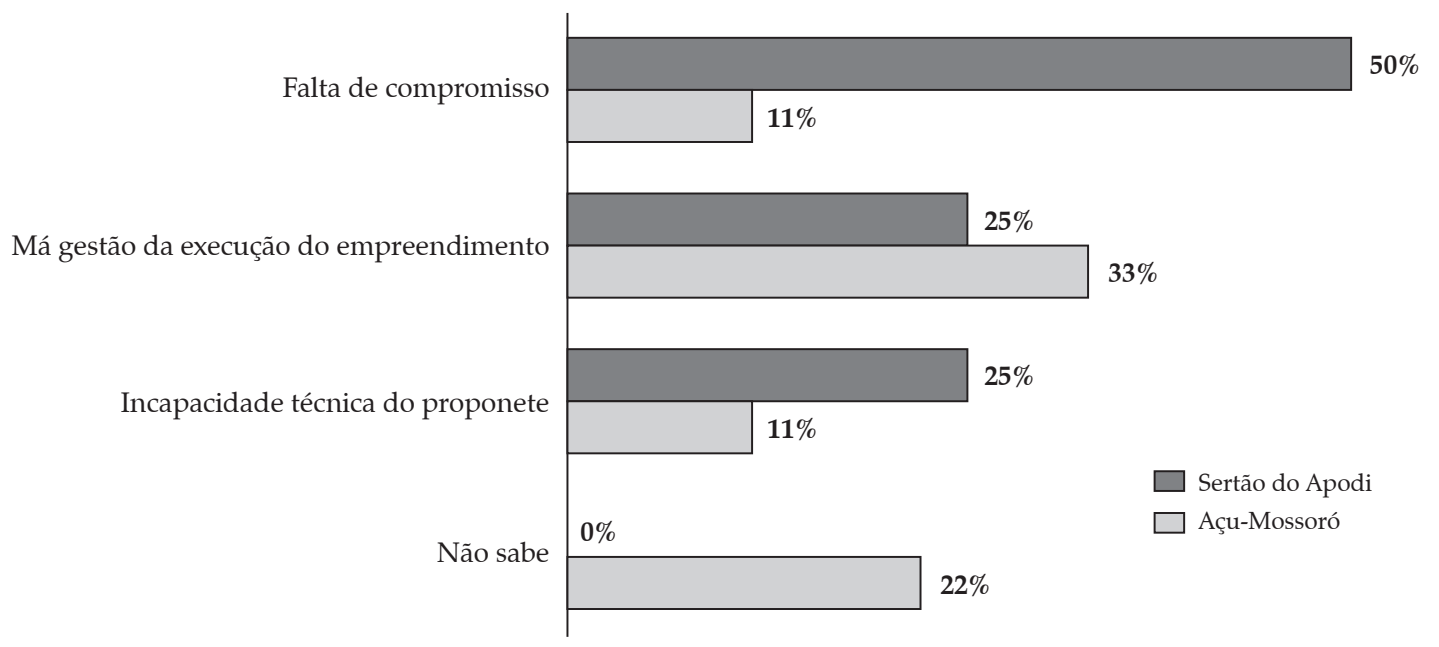

Fonte: Pesquisa de campo, 2012. 
Estadual de Desenvolvimento Rural (Cedrus) serão responsáveis pelo monitoramento e fiscalização para a garantia do uso devido dos bens adquiridos, isto é, devem assegurar o uso de forma coletiva tanto da estrutura de produção como a de beneficiamento e de comercialização dos produtos da agricultura familiar.

A Comissão Permanente de Gestão Local de cada município que sediar projetos financiados pelo Proinf efetuará o cadastramento dos agricultores familiares e o levantamento da produção, do beneficiamento e da comercializada, visando credenciá-los para utilização eficiente da unidade de produção construída (entrepostos de mel, casas de pescados, usina de leite etc.) e dos equipamentos adquiridos. A Comissão Permanente de Gestão Local deverá informar constantemente, ao Colegiado e à proponente, sobre esse cadastramento, e este deve ser sempre atualizado. A
Comissão será responsável ainda pela organização da logística local das unidades de produção e dos equipamentos, estabelecendo regras de uso equânime, com a definição, por exemplo, de cronogramas para rodízios, usos compartilhados dos diversos grupos de agricultores, além de estabelecer mecanismos para manutenção e conservação dos bens.

Entretanto, a pesquisa mostra que este arranjo institucional, ao longo dos dez anos de política, não tem dados respostas eficientes, como mecanismo de gestão social, para a inclusão produtiva e a dinamização econômica, especialmente quanto à gestão dos projetos estruturantes do Proinf nos territórios. Em relação aos indicadores, a avaliação de cada uma das variáveis calculadas varia entre 0 (zero) e 1 , sendo 1 a melhor avaliação e 0 (zero), a pior avaliação. No Território Sertão do Apodi, como mostra a Figura 7, a participação

Figura 7. Indicadores gerais de gestão dos projetos do Território Sertão do Apodi Índice de participação dos beneficiários na gestão do projeto

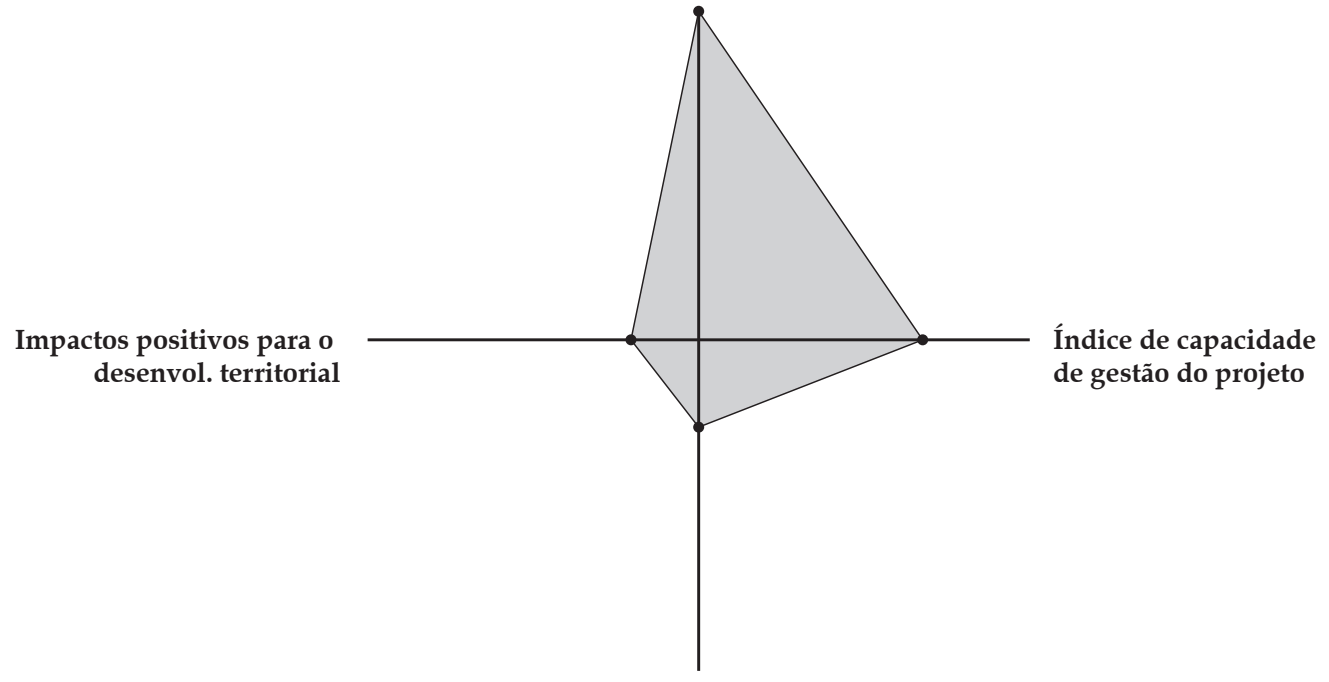

Índice de variação do perfil do público apoiado e atendido pelo projeto

\begin{tabular}{|l|l|}
\hline \multicolumn{1}{|c|}{ Indicadores Gerais de Gestão do Projeto } & $\mathbf{0 , 3 2 5}$ \\
\hline Índice de participação dos beneficiários na gestão do projeto & 0,607 \\
\hline Índice de capacidade de gestão do projeto & 0,417 \\
\hline Índice de variação do perfil do público apoiado pelo projeto & 0,159 \\
\hline Impactos positivos para o desenvolvimento territorial & 0,119 \\
\hline
\end{tabular}

Legenda: 0,00 - 0,20 = Crítico; 0,20 - 0,40= Ruim; 0,40 - 0,60= Regular; 0,60 - 0,80= Bom; $0,80-1,00=$ Ótimo.

Fonte: SGE/MDA (2011). 
dos beneficiários na gestão do projeto alcançou o indicador 0,607 (bom), e a capacidade de gestão do projeto obteve 0,417 (regular). Entretanto, a variação do perfil do público apoiado pelo projeto alcançou 0,159 (crítico) e, por último, os impactos positivos para o desenvolvimento territorial ficaram com o nível mais baixo, chegando a 0,119 (crítico).

Desta forma, transcorridos dez anos, a pesquisa revela que não existe uma estrutura de produção econômica (unidades de beneficiamento ou agroindústrias) em operação, resultado das ações do Proinf nos dois territórios, as quais visam a inclusão produtiva e à dinamização econômica. Neste contexto, a pesquisa aponta para um processo de desestruturação do ambiente institucional dos territórios, em razão da desmotivação dos membros dos Colegiados e da descrença dos agricultores familiares. Todavia, a análise da política de desenvolvimento territorial é fundamental para a continuidade do Proinf por parte dos governos, devendo ser realizada continuamente e com vistas a perceber seus avanços e seus limites considerando aspectos sociais, econômicos, de eficiência e de gestão. Porém, analisar políticas públicas por vezes significa estudar o governo em ação, ou melhor, o governo em questão. E igualmente aos governos, as políticas públicas são dinâmicas; portanto, os procedimentos metodológicos e seus pressupostos devem ser capazes de perceber tais peculiaridades e respeitar as diversidades inerentes a cada território e de cada processo.

\section{Considerações finais}

Neste artigo, a pesquisa constatou que têm sido feitos, nos dois territórios, esforços comuns no sentido de valorizar a agricultura familiar a partir de processos de agregação de valor dos seus produtos e da sua inserção em mercados, bem como elaboradas estratégias para superar entraves no acesso e na gestão das políticas. Para a pesquisa, tanto no Território Açu-Mossoró como no Sertão do Apodi, as ações do Proinf apontam para a reprodução de receitas antigas que lembram a abordagem Community Driven Development dos anos 1980 e dos CMDRs dos anos 1990, apesar do avanço significativo com a criação das instâncias dos Colegiados Territoriais nos anos 2000, em que o não desenvolvimento se mantém residindo, em certa medida, na abordagem coletiva dos programas financiadores do desenvolvimento.

A pesquisa revelou que deficiências da gestão social quanto ao modus operandi do arranjo institucional dos Colegiados Territoriais responsáveis pelas ações de inclusão produtiva contribuem para que a dinamização econômica não tenha acontecido por meio exclusivamente do Proinf. Neste sentido, constata-se, depois desses dez anos de política territorial, que o ambiente institucional dos territórios encontra-se ainda frágil e desestruturado, posto que, além de os empreendimentos econômicos não funcionarem, grande parte dos Colegiados Territoriais encontra-se desacreditada e os agricultores familiares descrentes quanto às ações de estruturação econômica do Proinf. Experiências anteriores vivenciadas pelos membros do colegiado da sociedade civil, a exemplo do Pronaf "Infraestrutura e Serviços" operado pelos CMDRs, tiveram mais êxito, mesmo sendo executados individualizados no âmbito do município, e que não configurava projetos territoriais, com pouca ou nenhuma participação dos beneficiários, e em que os projetos eram executados com mais agilidade. Todavia, com o Proinf verificou-se que, mesmo com o esforço coletivo na elaboração da proposta via Colegiado Territorial, seus membros não obtiveram êxito quanto à governança do arranjo institucional de gestão social previsto entre poder público (proponente) e sociedade civil.

Nota-se que as principais decisões ou ações de desenvolvimento rural continuam sob a responsabilidade dos gestores públicos (estaduais ou municipais) que, com exceção de alguns, demonstram desinteresse pelas ações de desenvolvimento territorial. A pesquisa constatou a necessidade de criar estratégias de envolvimento dos gestores públicos e das universidades, que possam resultar na maior eficiência das ações de 
inclusão produtiva e de gestão social e, consequentemente, na dinamização econômica. Além disso, é impar a necessidade de dotar de mais qualidade os projetos elaborados e inseridos no Siconvi, assim como estudos de viabilidade na definição dos municípios onde os projetos serão implantados. Cabe ainda ressaltar a importância de maximizar formação e capacitação em cooperativismo, como forma de fortalecer o ambiente e o arranjo para gestão dos projetos em andamento, considerando a continuidade e sua capacidade de operação. Estas considerações podem contribuir para minimizar as fragilidades encontradas nos territórios Açu-Mossoró e Sertão do Apodi (RN).

Quanto à estruturação econômica nos territórios Açu-Mossoró e Sertão do Apodi, a pesquisa constatou que o financiamento por meio do Proinf não tem sido satisfatório. No entanto, apesar deste cenário, cabe considerar e reconhecer que vem sendo construído por meio de outros financiadores um processo de estruturação econômica e de organização coletiva nos dois territórios. São ações além das que deveriam ser financiadas pelo Proinf que vêm fazendo surgir empreendimentos e dispositivos coletivos, e iniciando um processo interessante de dinamização econômica. São exemplos de sementes de uma transição no sentido de Ploeg et al. (2004), que têm possibilitado o surgimento dos dispositivos coletivos que brotam a partir das necessidades dos próprios agricultores familiares. São cooperativas, associações, redes de comercialização etc. que surgiram na esteira das políticas territoriais e encontram-se envolvidos nas discussões da política territorial. Na verdade, essas organizações e atores territoriais sempre demandaram recursos do Proinf e têm se revelado instrumentos importantes na geração de oportunidades de inclusão produtiva nos dois territórios estudados, em estratégias que lembram a labour-driven intensification, definida por Ploeg (2008). E estas oportunidades surgem por meio da organização coletiva, da agregação de valor pelo surgimento de várias unidades de agroindústrias familiares, e do acesso a mercados, sinalizando para um ambiente favorável ao surgimento de novidades (novelty production) e de inovações (innovation production).

Dessa forma, constata-se que a política territorial, apesar das suas limitações do arranjo institucional dos Colegiados Territoriais, assim como da abordagem coletiva dos programas, neste caso o Proinf, tem contribuído na formatação de um ambiente favorável para a discussão e implantação de políticas de desenvolvimento territorial, mesmo sem o alcance desejado do Proinf. Assim, os atores territoriais, em especial os agricultores familiares, têm construído estratégias a ponto de conseguir articular parcerias no sentido de estruturar cadeias produtivas territoriais da agricultura familiar. E essas estratégias têm sido viabilizadas por outros meios, através de outros arranjos institucionais de apoio à agricultura familiar, a exemplo da Fundação Banco do Brasil (FBB), do Banco Nacional de Desenvolvimento Econômico e Social (BNDES), da Petróleo Brasileiro S.A. (Petrobrás), e da Cooperação Internacional por meio da FIDA, da ICO da Holanda, da FAO, Universidades, entre outros).

Como exemplos concretos, a pesquisa destaca, no Território Açu/Mossoró, as feiras da agricultura familiar organizadas por redes e cooperativas, a organização produtiva da fruticultura, criação de animais de pequenos porte, o beneficiamento artesanal de castanha de caju, e a legalização de duas unidades de extração de mel e o acesso ao mercado institucional, através do PAA e do PNAE, Neste período, no Território Sertão do Apodi, brotaram cinco cooperativas da agricultura familiar, organizando a cadeia do mel, com 500 agricultores familiares cooperados, e tendo sido estruturadas e legalizadas duas casas de mel, um entreposto em construção, cinco fábricas de beneficiamento de castanha de caju e quatro casas de polpa de frutas.

Por fim, acredita-se que a definição desse cenário de construção da estrutura de produção econômica, como descrito acima, afirma ainda mais a necessidade de unir esforços no sentido de ofertar mais recursos do Proinf (quanto a financiar mais projetos de infraestrutura), assim como de buscar formas para melhorar e aperfeiçoar o 
arranjo institucional dos Colegiados Territoriais (quanto às ações de acesso às políticas territoriais, bem como à governança e gestão social). Sugere-se, portanto, uma redefinição da abordagem coletiva do Proinf, a exemplo de estimular a ação coletiva e exercer a paridade também no acesso aos editais para a participação privada, em que os projetos possam ser elaborados e implantados por meio das cooperativas, associações, redes etc. Neste caso, a contratação e execução do processo de estruturação econômica da agricultura familiar deixam de ser exclusividade dos gestores públicos, e a paridade entre poder público e sociedade civil passa a ser um ponto que visa, acima de tudo, a dinamização econômica dos territórios. Por outro lado, a metodologia da SDT deve criar mecanismos para atrair os gestores públicos para os Colegiados Territoriais, buscando construir maior sintonia de participação entre as instâncias dos Colegiados Territoriais, os elaboradores de projetos, os gestores públicos e a Caixa Econômica Federal, pois, sem um processo eficiente de governança entre estas partes, dificilmente a política de desenvolvimento territorial logrará êxito.

\section{Referências}

ABRAMOVAY, R. Conselhos além dos limites. Revista Estudos Avançados, São Paulo, v. 15, n. 43, set./dez. 2001.

Apoio a Projetos de Infraestrutura e Serviços em Territórios, PROINF. Manual Operacional do Proinf 2012: ação orçamentária de apoio a projetos de infraestrutura e serviços em Territórios Rurais. Brasília/DF, p. 54, 2012. Disponível em: <http://portal.mda.gov.br/portal/ arquivos/view/Manual_Proinf_2012.pdf>. Acesso em: 30 mar. 2014.

BRASIL. Lei nº 11.326, de 24 de julho de 2006. Estabelece as diretrizes para a formulação da Política Nacional da Agricultura Familiar e Empreendimentos Familiares Rurais. Disponível em: < http://www.planalto.gov.br/c civil 03/ ato2004-2006/2006/lei/111326.htm>. Acesso em: 02 fev. 2012.

BRUNORI, G. et al. Towards a conceptual framework for agricultural and rural innovation policies. Projeto Insight. 27p., 2009.
CONTERATO, M. A. et al. Mercantilização e mercados: a construção da diversidade da agricultura familiar na ruralidade contemporânea. In: SCHNEIDER, S. e GAZOLLA, M. (Org.). Os atores do desenvolvimento rural: perspectivas teóricas e práticas sociais. 2. ed. Porto Alegre: Editora da Universidade Federal do Rio Grande do Sul, 2011.

LEITE, S. P. e WESZ JUNIOR, V. J. Um estudo sobre o financiamento da política de desenvolvimento territorial no meio rural brasileiro. Revista de Economia e Sociologia Rural (Impresso), v. 50, n. 4, p. 645-666, 2012.

MOURA, J. T. V. Os Conselhos Municipais de Desenvolvimento Rural (CMDRs) e a Construção Democrática: esfera pública de debate entre agricultores familiares e o Estado? Organizações Rurais e Agroindustriais, v. 9, p. 241-255, 2007.

NUNES, E. M. et al. O Índice de Capacidades Institucionais (ICI) como mecanismo da gestão social e da governança nos territórios rurais. Planejamento $e$ Políticas Públicas, v. 42, p. 301-330, 2014.

e SCHNEIDER, S. Reestruturação Agrícola, Instituições e Desenvolvimento Rural no Nordeste: a diversificação da agricultura familiar do Polo AçuMossoró (RN). Revista Econômica do Nordeste, v. 44, p. 601-626, 2013.

OOSTINDIE, H. e BROEKHUIZEN, R. von. The dinamic of novelty production. In: PLOEG, J. D. van der e MARSDEN, T. (Eds.) Unfolding webs: the dynamics of regional rural development. Assen: Van Gorgum, 2008.

PERICO, R. E. Identidade e território no Brasil. Brasília/ DF: IICA, p.209, 2009. Disponível em: < http://www. iica.org.br/Docs/Editais/SolicitCotacoes_IICA_00552009_Anexo.pdf>. Acesso em: 20 mar. 2014.

Plano Territorial de Desenvolvimento Rural Sustentável, PTDRS. Sertão do Apodi e Açu/Mossoró, 2010.

PLOEG, J. D. van der. The new pensantries: struggles for autonomy and sustainability in an era of empire and globalization. London: Earthscan; Sterling VA, 2008.

. e WISKERKE, J. S. C. (Eds.). Seeds of transition: essays on novelty production, niches and regimes in agriculture. Assen: Van Gorcun, 2004.

SABOURIN, E. Dispositivos coletivos de apoio à produção e dinâmicas territoriais. Raízes, v. 28-29, n. 1, p. 154-165, 2010.

SACCOMANDI, V. Agricultural market economics: a neoinstitutional analysis of the exchange, circulation and distribution of agricultural products. Assen: Van Gorcum, 1998. 
SANTOS JUNIOR, S. e WAQUIL, P. D. A influência de fatores econômicos, institucionais e sociais na inserção de agroindústrias rurais em Santa Catarina. Revista de Economia e Sociologia Rural (Impresso), v. 50, p. 263-284, 2012.

SCHNEIDER, S.Aabordagem territorial do desenvolvimento rural e suas articulações externas. Revista Sociologias, Porto Alegre/RS, v. 11, p. 88-125, 2004. Disponível em: <http:// www.scielo.br/pdf/soc/n11/n11a06>. Acesso em: 2 mar. 2014.

STUVIER, M. e WISKERKE, J. The VEL and VANLA Enviromental Co-operatives as a Niche for Sustainable Development. In: WISKERKE, J. S. C. e PLOEG, J. D. van der (Eds.). Seeds of transition: essays on novelty production, niches and regimes in agriculture. Assen: Van Gorcun, 2004. 
